Illinois State University

ISU ReD: Research and eData

Theses and Dissertations

3-7-2015

\title{
An emotional spark: Exploring the role of emotions in organizational training programs and beyond
}

Olivia Loren Hook

Illinois State University, olhook@ilstu.edu

Follow this and additional works at: https://ir.library.illinoisstate.edu/etd

Part of the Communication Commons

\section{Recommended Citation}

Hook, Olivia Loren, "An emotional spark: Exploring the role of emotions in organizational training programs and beyond" (2015). Theses and Dissertations. 337.

https://ir.library.illinoisstate.edu/etd/337

This Thesis is brought to you for free and open access by ISU ReD: Research and eData. It has been accepted for inclusion in Theses and Dissertations by an authorized administrator of ISU ReD: Research and eData. For more information, please contact ISUReD@ilstu.edu. 


\title{
AN EMOTIONAL SPARK: EXPLORING THE ROLE OF EMOTIONS \\ IN ORGANIZATIONAL TRAINING PROGRAMS \\ AND BEYOND
}

\author{
Olivia L. Hook
}

92 Pages

May 2015

This study sought to identify which emotions are experienced during initial training periods in organizations, and how these emotions affect job satisfaction and employee intent to leave in the long-term in these organizations. Scales were developed to measure 20 positive and negative emotions experienced during initial training programs, how likeable and clear their trainer was perceived to be, and employee perceptions of job satisfaction and intent to leave. 
AN EMOTIONAL SPARK: EXPLORING THE ROLE OF EMOTIONS

IN ORGANIZATIONAL TRAINING PROGRAMS

AND BEYOND

OLIVIA L. HOOK

A Thesis Submitted in Partial Fulfillment in the Requirements for the Degree of

MASTER OF SCIENCE

School of Communication

ILLINOIS STATE UNIVERSITY 
(C) 2015 Olivia L. Hook 
AN EMOTIONAL SPARK: EXPLORING THE ROLE OF EMOTIONS

IN ORGANIZATIONAL TRAINING PROGRAMS

AND BEYOND

OLIVIA L. HOOK

COMMITTEE MEMBERS:

Kevin R. Meyer, Chair

Caleb T. Carr

Lance R. Lippert 


\section{ACKNOWLEDGMENTS}

Writing a Master's thesis is a daunting task, one I was initially sure I would never attempt. I am so proud to have traveled this journey and written this research study with the completion of my Master's degree at Illinois State University. Of course, a project of this caliber could not be done without the help and guidance of some very talented and patient individuals.

First and foremost, I would like to thank Dr. Kevin Meyer. I am so impressed with the work ethic of this man, and he always has the best interest of his mentees and the School of Communication in mind. From staying on campus to meet with me at any time, responding to my many frantic emails at all hours of the night, to holding my hand along the way and giving me the extra push I needed, I cannot put into words what Dr. Meyer's unwavering patience and assistance has meant to me. Even with the thousand other hats Dr. Meyer wears, I always felt like a top priority. Without you, Dr. Meyer, I would be lost in this process. I am lucky to have been one of your mentees. Thank you for taking me from a first year graduate student petrified of quantitative research methods to a confident communication scholar and graduate from this incredible Master's program.

Next, I owe a huge thank you to Dr. Caleb Carr. I first met Caleb my senior year of college in his professional public speaking course. Since that course, he continues to make me believe that he is the smartest, most interesting person I know. I genuinely enjoy spending time with you, both in and out of the classroom. Thanks for always 
believing in me and pushing me to believe in myself and my abilities. You always push me to strive for more. I will miss your snarky jokes and your life advice that I seek so often.

I would also like to thank Dr. Lance Lippert. I have known Lance for several years now, and I am so grateful for his kindness, insight, and his corny jokes. He has always been one to ask about how things outside of school are going or prep me for a 'real world' interview. I appreciate all of the support and guidance you have given me over the last few years, and for pushing me to apply to graduate school in the first place.

I would like to thank Dr. Sandra Metts. I have been fortunate enough to take each of the courses that Dr. Metts offers at Illinois State both at the undergraduate and graduate levels. Beginning with her course on communication and aging my senior year, I was hooked on Dr. Metts. Not only is Dr. Metts a nationally recognized scholar and celebrity at our annual conferences, but she is also a genuine and caring person. I strive to have the same energy and compassion that she does with her students each and every day. The original idea for this study was a result of Dr. Metts' emotions seminar. I learned more in that class than any other when it comes to real world application. For that I am thankful.

I am grateful to consider all of these incredible scholars my mentors and now friends. You are the reason I will miss Illinois State.

Patty, or Miss Patty as I lovingly refer to her, is the backbone of the School of Communication. I have felt attached to Patty from the day I sat in her office and she explained her passion for the TRANSFORMERS program the semester before I started graduate school. I have learned so much from her and that program, and for that I am 
grateful. There is not one graduate student who has not been saved by Patty in some way. Miss Patty has been our rock and our saving grace over the last two years. I cannot imagine going through this process without Patty. Thank you for always keeping us in check. Thanks for always keeping your door open, no matter how much we drove you crazy. I will miss you greatly.

I would like to thank my graduate cohort. Over the last two years, I have grown personally and professionally alongside some of the smartest, most hard-working individuals I have ever met. Thank you for sharing my desire for success and growth, both personally and professionally. I am grateful not only for the nights out at Maggie's or singing karaoke at Lunker's, but also for the countless times in the graduate office where we bounced ideas off each other and clarified theory for hours on end. I am excited to see what the future holds for these strangers who turned into lifelong friends. I am confident that each and every one of you will find success.

Specifically, I would like to thank Kody Frey. I partnered with Kody on a paper in my first graduate seminar, and learned more from him than from any other of my colleagues. Your perfectionist work ethic is astounding; no matter how much I tease you for it. Since we began this process you have been a friend and confidant. You continue to impress me with your incredible mind, kind heart, and Southern charm. Thank you for your continued love and support and for always making me laugh. I am certain that you will find great success in the future, and I can't wait to continue our journey together.

Lastly, I would like to thank my "baby" brothers, Tyler and Luke. Thank you for your love and support, and for continuing to make me such a proud older sister. I don't 
tell you often enough how much you mean to me, and how grateful I am to have you both for brothers. I cherish our time spent together, and I love you both very much.

I would like to dedicate this work to my father, Jim Hook. He is more than my dad; he is my personal cheerleader and my rock. Thank you for passing down your ' gift of gab', the same gift that lead me to complete two degrees in communication and follow in your footsteps. I remember growing up being amazed at your wealth of knowledge. Thank you for always setting an example for Tyler, Luke, and I, and for your constant encouragement, love, and support. Even on the most difficult days, you are there to tell me how proud of me you are. I am so proud to be your daughter. You are the most selfless and loving person I know, and I owe my success thus far to you. This is for you, dad. I love you and appreciate you more than you will ever know.

O.L.H. 


\section{CONTENTS}

ACKNOWLEDGMENTS

CONTENTS

$\mathrm{V}$

TABLES vii

CHAPTER

I. REVIEW OF RELATED LITERATURE 1

Statement of the Problem 1

Emotions and Communication 3

Emotions versus Affective State $\quad 7$

Specific Emotional Experiences 9

Anger $\quad 9$

Fear $\quad 10$

Pride $\quad 10$

Happiness 11

Disappointment 12

$\begin{array}{ll}\text { Hurt } & 13\end{array}$

Broaden-and-Build Theory $\quad 14$

Emotions in Training Programs 18

Initial Training and Orientation Programs 21

Newcomer Socialization $\quad 23$

Job Satisfaction and Employee Intent to Leave 28

Hypotheses and Research Question 31

Summary 32

II. METHODOLOGY 33

Participants $\quad 33$

Procedures $\quad 35$

$\begin{array}{ll}\text { Measurement } & 37\end{array}$

$\begin{array}{ll}\text { Survey Instrument } & 37\end{array}$ 
Validity and Reliability

Emotions Scale

Job Satisfaction Scale

41

Intent to Leave Scale

Socialization Scale

Trainer Clarity and Likeability

Data Analysis

III. RESULTS

Job Satisfaction

Intent to Leave

Newcomer Socialization

63

Summary

IV. DISCUSSION

Summary of Findings

Factor Analysis

Regression Models

Implications

Practical Implications

Theoretical Implications

Limitations

75

Future Research Directions

76

Conclusion 


\section{TABLES}

Table Page

1. Factor Loadings for Emotions Scale

2. Factor Loadings for Job Satisfaction Scale

3. Factor Loadings for Intent to Leave Scale

4. Factor Loadings for Socialization Scale

5. Factor Loadings for Trainer Clarity Scale

6. Factor Loadings for Trainer Likeability Scale

7. Independent Samples $t$-test Comparing Early and Late Responders

8. Beta Weights for Job Satisfaction/Nature of Work Model

9. Beta Weights for Job Satisfaction/Communication Model

10. Beta Weights for Intent to Leave/Values Model

11. Beta Weights for Intent to Leave/Volunteer Model

12. Beta Weights for Intent to Leave/Planning Model

13. Beta Weights for Socialization/History Model

14. Beta Weights for Socialization/Politics Model

15. Beta Weights for Socialization/Performance Proficiency Model 


\section{CHAPTER I}

\section{REVIEW OF RELATED LITERATURE}

\section{Statement of the Problem}

The way emotions are experienced and expressed impact communication in many contexts. The current study focused on emotions in the workplace and their long-term effects in the organizational setting. Emotion and communication are inherently intertwined as communicators experience, construct, and express feelings toward others and their environment (Lupton, 1994). The study of emotions is typical in the field of psychology, but the expression of these diverse emotions is directly related to communication. Employees are constantly communicating with their peers and, thus, emotions come into play in the workplace. During initial training periods, employees are socialized into their new organization (Jablin \& Krone, 1987). This socialization process involves communication between the trainer and the new employees. Therefore, the emotions experienced as a response to the training should be further explored. This study explored the experience of emotions in the workplace, especially how these emotions in initial training programs affect an organization in the long run, based on the satisfaction and intent to leave of individual employees.

Examining the emotions experienced during initial training programs is an important and interesting way to examine and thus predict organizational success. The emotional undercurrent in organizations is impacting future success. Organizational 
communication scholars always talk about a combination of the variables that make up organizational success, but the emotional aspect has been ignored. Emotions need to be paid more attention due to their long-term consequences (Fredrickson, 2004). Research specifically on emotions in the organizational setting is relatively new to the communication discipline. Much research has been done on emotions in the workplace, but does not indicate whether workplace emotions have an effect on the above dimensions of organizational satisfaction and intent to leave.

The present study attempted to understand the effect of emotions experienced during initial training programs, controlling for trainer likeability and clarity in explaining job-related tasks. This study investigated workplace emotions, namely those likely to be experienced during new hire training programs, and their connection to organizational satisfaction and intent to leave the organization. The general purpose of this study is to understand how the emotions experienced in initial training periods or programs affect employee intent to leave and long-term satisfaction in an organization. To do so, the study focused on the significance of the positive and negative emotions employees experience in the workplace, and how those emotions predict intent to leave and long-term satisfaction. To do so, the belief outlined in broaden-and-build theory that positive emotions have the ability to take one's mind off of immediate needs and stressors and minimize or even mute other negative emotions was tested (Fredrickson, 2004).

Broaden-and-build theory promotes the idea that "positive emotions broaden an individual's momentary thought-action repertoire," which, in turn, "promotes the discovery of different creative actions" (Fredrickson, 2004, p. 1367). If one's scope of 
positive emotions is broadened, resilience for future will be built. These resources then function as a type of reserve that can be drawn from at later times, if necessary. Doing so can improve the odds of successful coping in the workplace. The present study tested this theory in an organizational context, specifically during initial training programs for new employees. The study sought to discover if early-on emotional experiences in new organizations can predict the employee's future in that organization.

Ultimately, this study should have practical implications for any and all organizations that utilize initial training programs for new employees. The current study helps demonstrate whether or not organizational training programs are effective, depending on the emotional reactions they illicit from new hires. The content of the training and the trainer have an impact on the effectiveness of the training program, but the emotional experience by the new employees has been ignored, until now. This study argues that there is a long-term effect of the new employees' emotions in the organization. This research will help inform, improve, and refine training programs in the future.

\section{Emotions and Communication}

Emotion and communication are inherently intertwined as communicators experience, construct, and express feelings toward others and in reaction to their environment. This relationship is apparent even in the workplace. Oftentimes, these emotions and the long-term effects they have on future organizational successes are ignored. Examining the emotions experienced during initial training programs is an important and interesting way to examine employee perceptions and intentions of the organization in which they work. This study differs from those looking at socialization as 
a predictor of organizational outcomes in that the emotions triggered by initial training programs and its subsequent outcomes are the emphasis.

Communication has both content and relational aspects (Watzlawick, Bavelas, \& Jackson, 1967). The content aspect refers to the meaning of the message, whereas the relationship aspect alludes to how the message sender views his or her relationship with the message receiver. When speaking of emotions, the focus is on the relationship aspect of communication. A large component of any message is the emotional tie the message sender sends along with the message. Depending on the relationship between the message sender and receiver, the emotions involved have the ability to change the message.

As Watzlawick et al. (1967) explained, there can often be confusion between the content and relationship aspects of a message. Therefore, the emotions behind any message are critical in many interactions in order to connect the content to the specific relationship. Within the relationship aspect of communication, individuals offer each other definitions of the relationship (Watzlawick et al., 1967). As expressed by Watzlawick et al., individuals are "unable to maintain emotional stability for prolonged periods in communication with themselves only" (p. 84). On the metacommunicational level, emotions serve to show another individual not only how one views the other, but also how one views oneself. Apart from the mere exchange of information, individuals must communicate with others for the sake of self-awareness. According to Andersen and Guerrero (1998), the experience and the expression of emotions are inherently communicative.

The most obvious connection of emotions and communication lies in the expression of emotions, both verbally and nonverbally. There is an "inherent 
inseparability of communication, emotion, and cognition" (Andersen \& Guerrero, 1998, p. 49). The vocal communication and the facial or nonverbal expression of the emotions individuals experience provide support for the claim that emotions are indeed communication (Andersen \& Guerrero, 1998). Scholars agree that emotional expression happens through diverse channels, including face, voice, and gesture (Andersen \& Guerrero, 1998). Expressing emotions, be it through verbal or nonverbal channels, communicates an individual's reaction to an event and, thus, an intention to act a certain way in the social environment (Johnstone \& Scherer, 2000). Johnston and Scherer claimed that expressing emotions represents a symptom of the state of the message sender, and a signal designed to elicit a response from the message receiver.

Much like the vocal communication of emotions, the nonverbal (e.g., by means of facial expression or body gestures) expression of emotions evokes fairly specific responses in message receivers (Keltner \& Ekman, 2000). However, Bruner and Tagiuri (1954) claimed the facial expressions of emotions alone leave much room for interpretation. Thus, the nonverbal expression of emotions is not as clear as the verbal expressions of the same emotions. The basic emotions have distinct facial expressions cross-culturally, such as a smile to indicate happiness (Keltner \& Ekman, 2000). It has been found that facial expressions of emotions are determined by context-specific social motivations (Fridlund, 1992). There are established links between facial expression and other markers of emotion, including the elicitation, timing, and measurement of these emotions (Keltner \& Ekman, 2000).

The experience of emotions in different environments, such as the workplace, serves social purposes. As previously demonstrated by Goffman (1961), individuality and 
emotions stem from the social roles that we hold. One thing theorists can agree upon is the attribution of social functions to emotions. Scholars believe that emotions play a role in solving problems of social living. The social-functional approach states that emotions help us to solve many of the basic problems of social living (Keltner \& Haidt, 2001). Keltner and Haidt argued against evolutionary theorists and say that emotions are socially learned responses constructed in the process of social disclosure according to concerns about our own identity, morality, and social structure. Social living presents humans and other social animals with problems whose solutions are crucial to survival. This is where emotions come into play. Our emotions are designed to solve such problems. Emotions solve these issues by coordinating social interactions, and elaborated emotions do so through specific processes according to culture.

The culture within which one lives has effects on the socializing of emotions. Culture determines both the emotions that will be expressed as well as what behaviors are acceptable in the expression of these emotions in certain situations (Johnson-Laird \& Oatley, 2000). However, many emotions are universal across cultures. Culture also influences which situations lead to particular emotions, and regulates the existence and experience of the more complex or blended emotions. Emotions are social because they oftentimes are experienced in reaction to another person. In other words, emotions are experienced as a reaction to some sort of social interaction, and are rarely experienced alone. Thus, in order for an emotion to be experienced, an individual must be exposed to some stimuli that then trigger some emotion or set of emotions (Morgan \& Heise, 1988). Emotions vary depending on the cultural context. However, this study does not look at emotions across cultures, but it is important to note this difference. 


\section{Emotions versus Affective State}

The definition of an emotion is one that has been debated for some time. Emotions are oftentimes confused with other terms describing feelings, such as affective states. Emotions are relatively brief states of arousal that are triggered by some type of stimulus (Knobloch \& Metts, 2013). Emotions "begin with a stimulus and include feelings, psychological changes, impulses to action, and specific, goal-directed behavior" (Plutchik, 2001, p. 346). These emotions can have a positive, negative, or a combination of positive and negative valence associated with them. Emotions are much more complex than just a state of feeling.

Scholars continuously debate the subcategories of emotions. However, many interpersonal scholars agree that emotions fit into three categories: basic/primitive, primordial/secondary, and social/elaborated emotions (Knobloch \& Metts, 2013). The first subcategory, the "basic" emotions, is comprised of those that are necessary for survival. The second subcategory of emotions, or the primordial emotions, requires a cognitive response. The final subcategory of emotions is called the social or elaborated emotions. This category is comprised of the most complex and mixed or blended emotions.

The "basic" emotions, is comprised of those emotions that are necessary for survival. These emotions are biological and innate in all of us. For example, fear is necessary for our protection, disgust saves us from eating rotten or dangerous food, and love makes a commitment between partners to raise offspring together. These basic emotions do not require cognition, and can be experienced by most animals. Our reactions to these basic emotions are a reflex, or automatic response set. 
The second subcategory of emotions, or the primordial emotions, requires a cognitive response. Whereas basic emotions trigger a reflex, primordial emotions trigger a cognitive realization (Morgan \& Heise, 1988). For example, in order to feel shame, an individual must be cognitively aware that others are judging the individual. Other primordial emotions include embarrassment and guilt. This second subcategory builds upon the initial category of primary emotions.

The final subcategory of emotions is called the social or elaborated emotions. This category is comprised of the most complex or mixed emotions. Such social emotions include emotions that may have a blend of positive and negative valence. For example, the emotion moral disgust is a social or elaborated emotion because it is more complex than the basic emotion disgust. It blends this basic emotion with a cognitive response (Knobloch \& Metts, 2013). Moral disgust could be an emotion felt if one sees someone abusing his or her pet. In this case, moral disgust is a cognitive reaction to an action of another.

Affective states need not be confused with the term emotions. Oftentimes, communication scholars incorrectly consider the two terms to be synonymous. Affective states last much longer than these brief emotions (Plutchik, 2001). These states can be categorized by long periods of extreme moods. Affective states such as depression, anxiety, stress, or optimism can last for quite some time, and are therefore not considered emotions. Emotions, unlike affective states, are triggered by some sort of external stimulus. Adversely, affective states often precede any stimulus (Andersen \& Guerrero, 2000). It is possible for there to be multiple, even conflicting emotions that are 
experienced during an affective state, thus the differentiation between emotions and affective states.

\section{Specific Emotional Experiences}

Although we experience a wide array of emotions in our daily routines, there are several emotions that are more likely than others to be experienced in the workplace. Due to the context of organizations, certain emotions are more likely to be experienced by employees than others (Grama \& Botone, 2009). For example, employees are unlikely, though not completely unable to, experience love in the workplace. Employees are most likely to experience emotions due to work-related stimuli. For the present study, several common workplace emotions will be described: anger, fear, pride, happiness, disappointment, sadness, frustration, and hurt.

\section{Anger}

Anger is a basic, negative emotion that results from a less than favorable communication interaction (Andersen \& Guerrero, 1998). Anger is one of the few emotions experienced from infancy. Most commonly, anger is experienced when something or someone interferes with an individual's execution of plans or attainment of goals. For example, if one co-worker belittles another co-worker's skills in front of the supervisor, this employee is likely to feel angry at the other. In this case, the first coworker reduced the second's power in front of the supervisor. According to Lemerise and Dodge (2000), anger organizes and regulates “internal processes related to self-defense, as well as regulating social and interpersonal behaviors" (p. 594). Anger is nearly always provoked by and experienced in reaction to another. When an individual is insulted, criticized, or provoked, a reaction is to become angry. Anger works in these situations to 
influence an individual's response to the situation. Andersen and Guerrero found that anger is an "overwhelmingly interpersonally induced emotion" (p. 60). It regulates interpersonal behaviors, and is regulated through social interactions between individuals (Oatley \& Jenkins, 1996). When anger is expressed in socially acceptable ways, it is associated with more favorable outcomes (Lemerise \& Dodge, 2000). For example, if an individual expressed their anger in a controlled way, the outcome of the emotional expression is less likely to be viewed as negative by others.

\section{Fear}

Fear is a negative emotion that is usually elicited by external forces or individuals. Fear may or may not have "roots in social interaction" (Andersen \& Guerrero, 1998, p. 60). This emotion may also be triggered by a past negative experience, such as an individual remembering a time when they were afraid of someone or something as a child. Fear is related to coping behavior, particularly escape and avoidance (Ohman, 2000). Fear is a basic emotion in that it is necessary for survival. Fear is what tells one to run to safety away from a wild animal. When all coping strategies fail, fear turns into anxiety, which is an affective state. The primary difference between fear and anxiety is that fear has an identifiable eliciting stimulus, whereas anxiety does not. According to Andersen and Guerrero (2000), fear is considered "post stimulus," which means it is triggered by, or comes after, some sort of negative stimulus. Adversely, anxiety is "pre stimulus," or a fear of something that has not yet, or may never happen.

\section{Pride}

Classified as one of the most social emotions, pride is often the result of another's approval that leads to positive self-evaluation (Andersen \& Guerrero, 1998). Pride can be 
conceptualized as joy over a behavior or action well done (Lewis, 2000). Pride oftentimes is not experienced until an achievement is recognized by significant others. When a boss or other superior in the workplace recognizes a job well done, the employee being recognized will feel a great deal of pride. For pride, the focus of pleasure is specifically related to a particular action, and therefore has the ability to be reproduced (Lewis, 2000). Although most often considered a positive emotion, too much pride can be seen negatively. Andersen and Guerrero explained how an overflow of pride has the ability to lead to negative emotions such as guilt, and others may consider such individuals cocky. Pride is a positive emotion when experienced in moderation.

\section{Happiness}

Happiness, one of the most desirable emotions, is deemed a positive emotional experience. Although happiness is an emotion that seems to be experienced quite often, an agreement of the definition of this emotion has not quite been reached. Averill and More (2000) claimed that some scholars consider happiness as a highly aroused state such as joy or elation, whereas others (Babad \& Walbott, 1986) consider happiness on a continuum, connoting contentment, tranquility, or even peace of mind. Although these definitions vary somewhat, all scholars can agree that happiness is indeed a positive, sought after emotion. According to Andersen and Guerrero (1998), happiness is most likely reached upon the attainment of a goal or a positive achievement of some kind. Happiness is particularly likely to occur when an individual's achievements are shared with, praised by, or told to others with whom an important interpersonal relationship is shared. Receiving love or affection from others is another major trigger of happiness or joy. Although love is not often felt in the workplace, affection is often shown between 
employees. Babad and Walbott (1986) claimed that happiness is particularly likely to occur in the context of such interpersonal relationships.

\section{Disappointment}

Disappointment is a negative emotion that is associated with either the presence of a negative outcome or the absence of a positive outcome (Dijk, Zeelenberg, \& Pligt, 1999). It can also be defined as non-achievement of an expected outcome. Although negatively valenced, disappointment has close ties to positive emotions such as hope and desire. The higher the initial positive emotion, the more disappointment is felt if the outcome is negative. Disappointment is an emotion that is rarely experienced alone. Sadness, anger, and frustration can result from disappointment. For example, if an employee feels confident that they will do well in an interview and receive a promotion, but does poorly and does not get promoted, they may experience some of these other negative emotions, as well as disappointment.

Both sadness, as it relates to disappointment, and anger usually relate to a goal in some way. "Sadness is associated with the belief that goals cannot be reinstated, whereas anger is associated with the belief that something can be done to reinstate the goal" (Dijk

et al., 1999, p. 132). Disappointment is often associated with frustration, or the failure of expectation or hope. However, studies show that disappointment is more associated with the absence of a positive outcome than the presence of a negative outcome, or other negative emotions like sadness, anger, frustration, and regret (Dijk et al., 1999). The presence or lack of an outcome determines which of these emotions is experienced.

Although mostly negative, disappointment has somewhat of a silver lining. Dijk et al. (1999) argued that disappointment is positive in situations where false dreams turn 
to reality. In such cases, hope emerges and becomes more rational and realizable in the future. Disappointment is studied most frequently as a negative emotion. However, Dijk et al. made an interesting connection from disappointment to hope, and alludes to disappointment's ability to be positively valenced.

\section{Hurt}

Hurt is a blended negative emotion. According to Feeney (2005), hurt is a combination of sadness and fear. There is "sadness at a felt loss, and fear of being vulnerable to harm" (p. 254). Another way to look at hurt is damage to the victim's view of the self as worthy of love. Common causes of hurt feelings include harsh words, the raising of sensitive issues, betrayed secrets, and special dates forgotten. Hurt can also affect an individual's beliefs about the availability and trustworthiness of others (Feeney, 2005). The negative emotion hurt reflects a specific theme of suffering in some way. Hurt feelings are rarely felt in isolation. Situations that induce hurt feelings usually trigger other negative emotions because they share a common negative affect (Feeney, 2005). Hurt is "elicited by relational transgressions that generally imply low relational evaluation," which evokes a sense of injury by threatening an otherwise positive sense of self (Feeney, 2005, p. 254). Scholars argue that in order to be emotionally hurt by someone, an individual must value the relationship that they have with the other person (Knobloch \& Metts, 2013). Therefore, someone whose relationship one dos not value cannot easily hurt that individual. For example, an individual's boss degrading them would be quite hurtful. However, if the clerk at the grocery store said something along the same lines, it would not cause hurt because relationship between the clerk and the individual is not one of value. Or, one can argue, that there is no interpersonal 
relationship between the individual and the cashier at all. Without an important interpersonal relationship, a transgression cannot occur.

\section{Broaden-and-Build Theory}

Broaden-and-build theory explains the idea that when an individual experiences positive emotions early on, they build skills and resources they can pull from and use later in times of need. The overall balance of an individual's positive and negative emotions has been shown to predict their judgments and even future well-being (Fredrickson, 2001). Fredrickson found that these positive emotions serve as markers of personal flourishing. The broaden component of this theory is the idea that "positive emotions broaden an individual's momentary thought-action repertoire" which, in turn, "promotes the discovery of different creative actions" (Fredrickson, 2004, p. 1367).

Positive emotions carry long-term benefits because this act of broadening creates lasting personal resources (Fredrickson, 2001). Broaden-and-build theory supports the idea that positive emotions serve as a reservoir from which we draw in times of need in order to manage threat. Negative emotions, however, prompt a smaller range of immediate survival-oriented behaviors. The adverse effects of negative emotions can be counteracted by other positive emotions. The build component of this theory explains how building our repertoire of positive emotions in turn builds an individual's personal resources, ranging from physical and intellectual to social and psychological (Fredrickson, 2004). These resources then function as a type of reserves that can be drawn from at later times when necessary.

Broaden-and-build theory has not yet been applied to the workplace. Thus, if we broaden our scope of positive emotions during initial training programs, it will build in us 
resilience to be used in the future when it may be necessary. Positive emotions that broaden-and-build theory focuses on include joy, interest, contentment, love, and others (Fredrickson, 2004). According to broaden-and-build theory, positive emotions can minimize or even mute negative emotions. Happiness, for example, broadens our habitual modes of thinking or acting by creating the urge to play, push the limits, and be creative. Happiness has the ability to help individuals feel comfortable taking risks in future situations. Using broaden-and-build theory, Cohn, Fredrickson, Brown, Mikels, and Conway (2009) found that people who are happier achieve better life outcomes, including financial success, supportive relationships, mental health, effective coping, and even physical health and longevity.

Scholars have tested the validity of broaden-and-build theory with a variety of relational contexts. For example, Cohn et al. (2009) used this theory within romantic relationships. Cohn et al. further indicated happy people become more satisfied not simply because they feel better but because they develop resources for living well, which can be carried over into the workplace. How employees cope with the emotions they experience in the workplace contributes greatly to the understanding of overall job satisfaction (Muchinsky, 2000). In the workplace, "the capacity to effectively cope with our emotions is highly related to interpersonal relations" (Muchinsky, 2000, p. 804). These interpersonal relationships that individuals create in the workplace also play a role in the harnessing of different emotions. Emotions have been found to have a direct influence on the decision of whether or not an individual withdraws from a situation (O’Neill, 2009). Wong, Yik, and Kwong (2006) stated that the drive individuals have to remove themselves from a situation in which they are experiencing negative emotions 
can lead to a decrease in commitment. This can be applied to an organizational context. Those employees who experience negative emotions in an organization are likely to have a decreased sense of commitment to the organization.

Interestingly, Galatzer-Levy et al. (2013) studied a police force to test the validity of broaden-and-build theory within a population who deals with dangerous and lifethreatening situations regularly examining police officers' emotions in their basic training program. Findings demonstrated that those officers who broadened their scope of positive emotions early on in their basic training were much more likely to be resilient after a potentially traumatic event, such as the death of a fellow officer or other traumatic loss. These officers built up a reserve of positive emotions prior to experiencing a traumatic event. Those who did not broaden their scopes of positive emotions were not nearly as resilient, or able to bounce back after a traumatic event.

Fredrickson (2004), in a longitudinal study of 180 Catholic nuns, found that the nuns that were happy and had experienced more positive emotions throughout their lifetime lived about 10 years longer than those who did not. In this case, the broaden-andbuild theory suggests that positive emotions actually produce more healthy individuals with overall better well-being. Broaden-and-build holds that positive emotions are so powerful that they can even fuel human flourishing, making individuals more socially integrated, knowledgeable, and effective (Fredrickson, 2004). Although Fredrickson focused strictly on the impact of positive emotions, she eluded to the effects of negative emotions. The experience of negative emotions carries direct and immediate benefits for an individual, but is mostly useful in life-threatening situations. The majority of professionals do not ever encounter such life-threatening situations, unless they are in a 
field such as police work. Schiffrin and Falkenstern (2012) focused on the implications that negative emotions have on individuals, in accordance with broaden-and-build theory. These scholars showed that higher levels of negative emotions predict decreases in social, physical, and psychological resources, or resilience, as well as increases in detrimental psychological outcomes such as perceived stress or even depression (Schiffrin \& Falkenstern, 2012).

Broaden-and-build theory can be applied to an organizational context, as well. Past studies have shown that "higher levels of positivity are linked with broader behavioral repertoires, greater flexibility and resilience to adversity, and optimal functioning or flourishing" (Fredrickson, 2001, p. 1374). Thus, the theory provides a sensible application to the workplace. Individuals experiencing positive emotions show thought patterns that are flexible, creative, integrative, open to new information, and efficient, all of which are beneficial in the organization (Fredrickson, 2001). Broadenand-build teaches us that organizational leaders' "efforts to cultivate positive emotions in their employees will help their organization avoid stagnation and achieve harmony, growth, and prosperity" (Fredrickson, 2000, p. 140). Research on broaden-and-build theory affords practical application in the workplace.

Positive emotions help in dealing with stressful events and moderating the effects of negative emotions, causing resilience in individuals. Not only do these positive emotions increase an individual's creativity and efficiency, but they also build resilience. Positive emotions fuel this resilience. Resilient individuals are said to bounce back from stressful experiences more quickly, both in personal and work situations (Fredrickson, 2001). The broaden-and-build theory can be applied to many different research areas and 
types of relationships. These positive emotions can increase job satisfaction by building resilience in individuals. Broaden-and-build theory has much utility in a variety of communication research fields. Understanding this theory is relevant to our understanding of success in so many contexts, especially the workplace. Broaden-andbuild theory lays the foundation for what happens later on, in the workplace as well as in other contexts. Individuals always go back to their original emotional experience. Thus, it stands to reason that broaden-and-build theory would hold true for new employee training programs as well.

\section{Emotions in Training Programs}

Emotions in the workplace are studied a great deal in a general sense. However, very little research has delved into the effects that emotions experienced during initial training programs have on employees long-term. The majority of research about emotions in the workplace delves into emotional labor. Emotional labor is the idea that workers are expected to display a certain range of positive emotions in the workplace to satisfy organizational role expectations for customers and co-workers (Hochschild, 1983). Employees exhibiting emotional labor can use either surface acting or deep acting to display these appropriate emotional responses. Surface acting is a practice where employees fake a smile in order to satisfy the expectation of a positive attitude, whereas deep acting requires more effort. Deep acting, in terms of emotional labor, requires an employee to trick themselves into feeling positive emotions by imagining a more positive situation or context (Hochschild, 1983). Unfortunately, much literature on emotions does not move past the idea of emotional labor. Though important, emotional labor does not explain long-term effects of the employees' emotional experience. Instead of focusing on 
the appropriate maintenance of emotions in the workplace, the present study will investigate the effects of emotions on their satisfaction, intent to leave, and perceived socialization into the organization.

According to Muchinsky (2000), emotions are at the core of the human experience, and since we spend the majority of our lives in the workplace, the connection between the two is inevitable. Fredrickson (2000) suggested that positive emotions produce optimal organizational functioning. Emotions are critical resources for individuals as they make sense of information in different contexts. In a rational sense, emotions should be at the forefront of organizational communication research.

Emotions are the most important resources of the individual and, thus, are displayed in almost every setting, including the workplace (Grama \& Botone, 2009). According to Grama and Botone, the benefits of emotive expressiveness are enormous for personal efficiency, but also for the organizational efficiency. Weiss and Brief (2001) suggested that daily emotional experiences affect work performance. Stratton, Kass, and Rotenberry (2011) stated, "feelings facilitate the construction of our reality and how we make sense of our organizational experiences" (p. 17). Goleman (2002) suggested that communication by means of emotive expression is more effective than verbal communication, in that it is faster and subtler.

According to many organizational communication scholars, recognizing existing emotions within organizations is essential (Grama \& Botone, 2009). Emotions in the organizational environment determine work experiences, cognitive interpretations, behavioral changes, and specific behaviors in the workplace, according to Mirela and Iulia (2013). Organizations that are "interested in maintaining a healthy emotional 
environment will cause less suffering and will obtain more efficiency and a more productive behavior" (Grama \& Botone, 2009, p. 315). The proper recognition and expression of emotions is vital in the workplace. On a daily basis, we experience a wide array of these emotions that can be both positive and negative. Emotions create meaning of our time in the workplace, as well as indicate how we are doing and what we want to do next (Fineman, 2003). Fineman wrote that both the characteristics and intensity of positive and negative emotional episodes that we experience in the workplace direct many of our behaviors and long-term attitudes.

Employees experience and express a variety of positive and negative emotions in the workplace. Many of these emotions are felt very strongly (Muchinsky, 2000). Positive emotions experienced in the workplace "can offer us some of the most gratifying experiences of our lifetimes, whereas negative emotions can represent some of the most vexing and hurtful experiences we endure" (Muchinsky, 2000, p. 803). Thus, these emotions experienced during our daily work routines carry much weight. Despite the evidence of such emotions in the workplace, the majority of them are rarely discussed at work. Managers, supervisors, and leaders in the workplace deal with the emotions of their employees regularly (Muchinsky, 2000).

These organizational researchers (Fineman, 2003; Grama \& Batone, 2009; Mirela \& Iulia, 2013) recognized that emotions influence nearly every aspect of our work lives. Daily work events experienced by each employee lead to the experience of both positive and negative emotions. These emotions then influence work attitudes such as job satisfaction, loyalty to the organization, and affect-driven behaviors such as impulsive actions that deviate from the norm (Ashkanasay \& Daus, 2002). Most employees feel and 
witness diverse emotions such as fear, anger, pride, pleasure, frustration, shame, and guilt; many of these on a daily basis (Stratton et al., 2011). These specific emotions, as well as others, play a role in employee motivation, leadership, politics, managerial decision-making, and even work group dynamics (Stratton et al., 2011). All of these factors play important roles in the satisfaction and intent to stay in an organization for employees. Thus, experiencing positive emotions early on in a new organization is vital, especially during initial training programs.

Emotions lie at the center of both attitude formation and employee behavior at the organizational level. Everyday events in the workplace that employees experience evoke different emotions, which in turn influence the way employees think about their jobs, their supervisors, and the organization as a whole (Ashkanasy \& Daus, 2002). Both workrelated and external factors have an impact and are relevant in enabling an employee's ability to emotionally adjust to the work environment (Mirela \& Iulia, 2013). Thus, organizations should be concerned with encouraging the expression of emotion that strengthen and maintain a favorable and efficient emotional climate. In turn, this encouragement of expressiveness increases a feeling of trust and openness among employees (Mirela \& Iulia, 2013). The expressing of emotions by employees can be highly beneficial in organizations. As a result, scholars seem to agree that encouraging emotive expressiveness, to an extent, boosts workplace morale and overall performance.

\section{Initial Training and Orientation Programs}

Training is an extremely large business in the United States. An estimated $\$ 200$ billion annually is spent on organizational training (Scannell \& Donaldson, 2000). Essentially, training is a simple solution to enhance organizational effectiveness 
(Scannell \& Donaldson, 2000). According to Scannell \& Donaldson (2000), training is the process of developing skills in order to more effectively perform a specific job or task. During the second phase of socialization, the encounter phase, one of the most important formal communication processes to occur is the organizationally designed orientation or training program (Bullis \& Bach, 2989). When organizational programs and systems, such as new employee training programs, are well-designed and work toward investing the newcomer in the company's goals and culture, they can be successful in enhancing commitment and reducing turnover (Allen, 1996). Thus, an employee's intent to leave decreases or even diminishes.

Training focuses on the development of certain skills, and emphasizes achieving a specific level of skill attainment (Klemmer \& Snyder, 1972). Another emphasis of training is on performance levels in order to perform a certain job. Thus, skills and therefore training for different jobs and organizations across industries differ. The focus for all training programs, however, is to teach a new employee the specific skill set they will need to complete a job effectively. During training programs, trainers seek to bring about some kind of change in their trainees. Trainers are most likely to bring about this change by teaching their employees the skills necessary to complete job tasks (Klemmer \& Snyder, 1972). After completing a training program, the employees have a repertoire of skills that they did not have before the training. Like so many other components of communication, training is a process.

It is important to distinguish initial training or orientation programs for new employees from those smaller scale trainings that constitute "continued education." These continued education trainings take the form of a sexual harassment training, ethics 
training, or training about new software or programs in the organization. Such training programs have to be completed by every employee, regardless of how long they have been a part of the organization. These continued education programs are viewed oftentimes as a burden to employees; additional time taken out of the otherwise busy workday. These programs are viewed as a somewhat frustrating job responsibility. Although these smaller training programs may trigger emotions in the employees, the emotional reaction or experience is unlikely to affect future job satisfaction or intent to leave the organization. It is accepted that these programs will come up from time to time in any organization and every employee must go through them.

For the purpose of this study, initial training programs for new employees were the context of interest. New employees are often subjected to these training programs before they begin their new position in the organization, or simultaneously while they begin working in their new position. They often last a few weeks, and are done with a group of other new hires.

\section{Newcomer Socialization}

The socialization process for new employees is an important one. Its effectiveness can determine the individual's success in the organization. Jablin and Krone (1987) describe socialization as an ongoing and cognitive process in which individuals and organizations adapt to one another. Bullis and Bach (1989) explained how socialization takes place gradually, and is not automatic or immediate. Socialization is marked by different turning points where new employees become more, and sometimes less, connected to their organization (Bullis \& Bach, 1989). Organizational socialization has

the ability to predict employee outcomes such as organizational commitment and job 
involvement (Madlock \& Chory, 2014). Due to the number of jobs, and therefore socialization processes, an individual will go through in their adult life, the examination of these socialization processes and their outcomes are of value.

Socialization processes can be very stressful for a new employee due to the amount of uncertainty they are experiencing in the new organization. The new employee must cope with differences between their expectations and the reality of their position and the organization as a whole (Madlock \& Chory, 2014). The new employee also does not yet have comfortable routines or social scripts for interacting with and predicting the actions of other employees, and they are unsure of the specific contributions that are expected of them in their new role (Madlock \& Chory, 2014). This ambiguity of their role in the organization, coupled with the uncertainty of the new job places added stress on the new employee.

Hart (2012) suggested that "one of the major purposes of organizational socialization is to inform new employees of organizational and unit practices, familiarize them with relationships within the organization, and instill the values of the organization" (p. 191). During the socialization process, communication between the new employee and others within the organization is crucial. During this time, the new employee is given vital information needed in order to assimilate and become familiarized with the work environment (Hart, 2012). These employees learn about the organization itself, but also about their role within it. Socialization is different for all new employees, and does not always follow a distinct pattern (Bullis \& Bach, 1989).

Employee socialization is a process that encompasses three phases. Socialization starts with the anticipatory phase, moves on to the encounter phase, and finishes with the 
metamorphosis phase. The encounter phase of socialization begins before entry into the organization. This phase encompasses both socialization to an occupation and socialization to an organization (Bowes \& Goodnow, 1996). Thus, the new employee is being socialized not only into the potential new organization, but also into their role or position within the organization. Individuals learn about what work is in a general sense from early on in life through watching adults go to work, by doing chores around the house, and even by completing homework assignments for school (Hoffner, Levine, \& Toohey, 2008). Once individuals have a grasp on what work is, they learn about particular occupation and then particular organizations that support that occupation. The media portrays idealized views of many occupations, such as doctors, lawyers, and teachers. These views of different occupations are often inaccurate. Once an individual has decided on an occupation, they begin researching different organizations. Research can be done through the organization's website, a campus career center, or job sites online (Hoffner et al., 2008). Potential employees gain information through these sites about the organization's mission, values, and goals. They may even read about the organization's financial situation, structure, or more specific areas such as the job responsibilities, salary, and social culture (Louis, 1980). The employment interview also happens during this phase. During the interview, aspects of the organization that the individual did not know before can be asked about. All of this information is encompassed by the encounter phase of socialization before a potential employee sets foot into the organization.

The next phase of socialization is the encounter phase. The encounter phase occurs at the organizational "point of entry," when a new employee first encounters life 
on the job (Louis, 1980). This is a sense-making stage for the new employee that can be very stressful. The new employee relies on past experiences, predispositions, even the interpretations of others within the organization to interpret life in this new organization (Hoffner et al., 2008). During this phase, an array of informal and formal communication processes occurs. This is the point at which new employees are immersed into the organizationally designed orientation or training program, the program that this study focuses on. This phase also involves a good amount of information-seeking on the part of the employee in order to get settled in their new role and organization.

The third and final phase of the socialization process is called metamorphosis. Metamorphosis is the "completion" of the socialization process (Jablin \& Krone, 1987). At this time, the new organizational member is accepted as an insider. This transition from organizational outsider to insider is what marks the metamorphosis phase. "During this stage, the recruit begins to become an accepted, participating member of the organization by learning new behaviors and attitudes and/or modifying existing ones" (Jablin \& Krone, 1987, p. 713). At this point in the socialization process, the employee is no longer considered "new." An employee has entered the metamorphosis stage once they have learned new behaviors that fit the organizational norms, or they have modified existing ones to fit the new organization (Gallagher \& Sias, 2009). It is important to note that the relationship between the employee and the organization is not static at this point; this relationship is always changing and moving. According to Kramer (1993), this phase model of socialization assists in the understanding of how individuals move from being new employees to integrated organizational members. 
New employees face a colloquial while adjusting to their new organization. During the initial stages of a new job, each new employee will take time to become adjusted in the organization. According to Jones (1986), during the socialization process, new employees go through common learning experiences designed to produce standardized responses to future situations. There is a great deal of uncertainty involved with beginning a new job. A main goal of every new employee is to reduce this uncertainty (Jones, 1986). The methods of socialization that organizations use "influence the way these individuals respond to their organizations" (Jones, 1986, p. 252). Thus, initial training programs, or the first chance for an organization to socialize their new employees, are vital.

Newcomers entering organizations may experience emotions such as shock or surprise, blended emotions, when their assumptions about how individuals interpret and respond to actions or events do not conform to those that already exist in their new organization (Jones, 1986; Morgan \& Heise, 1988). Flanagin and Waldeck (2004) showed how effective socialization processes reduce these uncertainties, help new employees establish productive relationships, and ensure that individuals and organizations benefit from their working relationship. Thus, newcomers may be tempted to reassess their initial assumptions about the organization and to seek additional information about why people in the organization behave as they do. These newcomers engage in such practices in order to reduce any uncertainty or anxiety surrounding the entry process (Jones, 1986). The ultimate goal of any new employee is to reduce their uncertainty about not only their role, but also the organization as a whole. Successful socialization into an organization has several substantial benefits, including job 
satisfaction, commitment to the organization, and longevity in the organization (Flanagin \& Waldeck, 2004). As a result of the socialization process, the new employee appears more committed to the organization by his or her acceptance of the organization's goals, values, and rules (Porter, Steers, Mowday, \& Boulian, 1974). In other words, a successful assimilation process is a predictor of both job satisfaction and employee intent to leave. Madlock and Chory (2014) found that employers who focus on a positive socialization process for their new employees, including the communication of organizational values, norms, role expectations, and goals, can expect employees who are committed not only to the job, but the organization as a whole. Committed employees lead to a decrease in an organization's turnover.

\section{Job Satisfaction and Employee Intent to Leave}

Job satisfaction and employee intent to leave have historically been positively correlated. A widely accepted and commonly used definition of job satisfaction is "a pleasurable or positive emotional state resulting from the appraisal of one's job or job experiences" (Locke, 1976, p. 1304). For the purpose of the current study, job satisfaction will refer to how enthusiastic or complacent an employee is about the duties of their position within an organization. What has not yet been focused on in communication research is the relationship that emotions have with both job satisfaction and employee intent to leave. If an employee experiences positive emotions early on in a new organization, they are more likely to be satisfied and, therefore, stay at the organization for a longer period of time. The relationship between emotions and long-term organizational outcomes needs to be one of greater focus and importance for organizations in the future for these reasons. 
Today, employees are bringing more abilities, higher expectations, and a greater desire for self- responsibility to the workplace than did generations past (Loher, Noe, Moeller, \& Fitzgerald, 1985). A number of factors affect an employee's job satisfaction, including but not limited to job-related responsibilities, pay, and how they feel their personal values align with those of the organization. According to Arslan and Acar (2013), job satisfaction is "accepted as the most important indicator of psychological health at work" (p. 283). Job satisfaction also influences how individuals describe their jobs. Satisfied employees may see their jobs as more "complex" than dissatisfied individuals (Loher et al., 1985).

There is a clear link between the emotions experienced in the workplace and an employee's long-term satisfaction in the organization. According to Judge, Bono, and Locke (2000) "skill variety, task significance, and other specific job characteristics," and the emotions experienced at the time, "lead to satisfaction with the job" (p. 239). Loher et al. (1985) supported this claim. These scholars argue that job satisfaction is directly impacted by the degree to which a job requires a daily amount of variety. Another component to this is whether or not an employee's job impacts the lives of others (Loher et al., 1985). Fredrickson (2000) urged leaders to cultivate positive emotions in their employees as a means of achieving not only individual, but also organizational growth, which leads to optimal functioning over time. This can be done if organizational leaders model positive emotional experiences for their employees, or by helping employees find positive meaning in their own work. Fredrickson explained that positive meaning in the workplace can be drawn from a multitude of experiences, such as those of competence, achievement, involvement, significance, or even social connection. Leaders should 
promote these experiences daily. According to Loher et al. (1985), one of an employee's most important work values is need for personal growth and development through his or her job. These scholars found that organizations can improve both employee performance and job satisfaction by providing opportunities for personal achievement, growth, and recognition. Job satisfaction has emerged as the most widely studied predictor of employee intent to leave in organizations (Liu, Mitchell, Lee, Holtom, \& Hinkin, 2012). A universal organizational goal is to decrease employees' intent to leave, thus decreasing employee turnover. Liu et al. (2012) explained how "job satisfaction is the key psychological construct leading to turnover" (p. 1360). When employees rate their job satisfaction highly or positive, employee intent to leave will tend to be low. This also means lower turnover. Low job satisfaction, on the other hand, jeopardizes employees' intent to stay in the organization. In other words, if job satisfaction is high in an organization, then employee intent to leave will be low, which also means low turnover; a plus for any organization.

Intent to leave is an organization's ability to keep employees in that organization. Employee intent to leave allows an organization to retain a pool of knowledge, and therefore, a competitive advantage (Larkin \& Burgess, 2013). Because employee intent to leave positively impacts organizational effectiveness and employee morale, leadership rightly seeks more effective ways to retain valued employees and sustain high performance in the organization (Liu et al., 2012). Thus, job satisfaction tends to increase employee intent to leave in organizations, as more satisfied employees are more likely to stay in their position and not take advantage of employment opportunities elsewhere. 


\section{Hypotheses and Research Question}

The variables, trainer likeability and clarity, will be held constant for the sake of the following hypotheses and research question. These variables, though important to consider for training programs, are not the focus of the current study. The emotional residue of the training program, or the new employees' reaction to the holistic training experience was the focus. Through holding trainer likeability and clarity constant, the emotions were able to emerge as predictors of the dependent variables. This study isolated how the initial training program elicits specific emotional responses from new employees, not any reaction strongly influenced by the trainer. The study took into consideration the training program itself and the emotions experienced by new employees because of it. Each of the following hypotheses and research question consider a mix of the positive and negative emotions experienced by new employees in these training programs.

Job satisfaction will likely be predicted by the emotions new employees experience in their initial training programs. According to broaden-and-build theory, the presence of positive emotions and absence of negative emotions lead to a future of resilience. In other words, the emotions experienced early-on lay the groundwork for an employee's ability to cope with future interactions and experiences. Such resilience will likely lead to employee satisfaction and, therefore, less likelihood of employee intent to leave. Consequently, two hypotheses are posited:

$\mathrm{H}_{1}$ : Greater levels of positive emotions experienced by new employees during initial training programs will predict later reports of increased job satisfaction. 
$\mathrm{H}_{2}$ : Greater levels of negative emotions experienced by new employees during initial training programs will predict later reports of decreased job satisfaction.

$\mathrm{H}_{3}$ : Greater levels of positive emotions experienced by new employees during initial training programs will predict decreased intent to leave the organization.

$\mathrm{H}_{4}$ : Greater levels of negative emotions experienced by new employees during initial training programs will predict increased intent to leave the organization.

Previous literature does not provide much insight as to the emotional connection to employee socialization. This study attempted to find the connection between emotions experienced in reaction to initial training programs and employee perceptions of socialization. Thus, the following research question is posed:

RQ: How do the emotions experienced by new employees during initial training programs predict employee perceptions of socialization?

\section{Summary}

The general purpose of this study is to understand how the emotions experienced in initial training periods or programs affect employee intent to leave and long-term satisfaction in an organization. To do so, the study focused on the significance of these emotions in order to predict employees' intent to leave their current job and long-term satisfaction by testing the belief outlined in broaden-and-build theory that positive emotions have the ability to take one's mind off of immediate needs and stressors and minimize or even mute other negative emotions. 


\section{CHAPTER II}

\section{METHODOLOGY}

\section{Participants}

To investigate the role emotions play in the workplace, working professionals who have participated in initial training programs for new employees have been surveyed. The participant pool consisted of a network or snowball sample of working professionals, starting in, but not limited to, Central Illinois and the Chicago metropolitan area. Professionals working at all size organizations and industries (e.g., for profit, nonprofit, corporate, academia, etc.) accessed an online survey to participate in the study. A total of about 200 working professionals was desired as participants; unfortunately, that goal was not met. Although there were upwards of 500 clicks on the survey link, only 115 of those clicks actually completed the survey. Efforts were made to ensure the participants reflect a range of time elapsed between their training program and the present time, focusing on those professionals who have been in their current position for one to two years.

A total of 115 participants completed the survey. The participant ages ranged from 18 to 59 years old, with a mean age of 23.16 years $(S D=10.44)$ and a mode of 18years. All participants disclosed their biological sex. There were 36 participants who were males (31.3\%) and 79 females (68.7\%). Many participants also disclosed their race or ethnicity. The majority of participants, 106 in total $(92.2 \%)$ were Caucasian, followed by Hispanic, Asian/Pacific Islander, African American, and other. There were four 
Hispanic participants (3.5\%), two Asian/Pacific Islanders (1.7\%), and one African American (.9\%). There were two participants who chose "other" for their race/ethnicity, which accounted for $1.7 \%$ of the participants. Participants disclosed their education level as well. The majority of participants, $81(70.4 \%)$, reported their highest level of education as a bachelor's degree. Fifteen participants (13\%) reported completing a Master's degree, $15(13 \%)$ reported completing a high school diploma or GED, and $4(3.5 \%)$ reported completing a doctoral degree. Finally, participants reported the industry in which they completed their training program. A total of 113 participants $(97.5 \%)$ reported the industry in which they worked at the time of their training program. Customer service was the most represented industry, with 36 participants $(22.9 \%)$, followed by communication, with 22 participants (14\%). Nineteen participants $(12.1 \%)$ of participants reported sales as the industry, $18(11.5 \%)$ reported finance and insurance, $14(8.9 \%)$ reported academics or teaching, $12(7.6 \%)$ reported marketing and advertising, 8 (5.1\%) reported technology and healthcare, and 7 (4.5\%) reported management. Only 3 participants (1.9\%) reported sports fields, 2 participants $(1.3 \%)$, reported consulting, and 1 participant $(0.6 \%)$ reported their industry as a church or religious organization, a nonprofit, parks and recreation, or engineering.

Additional information about participants was collected, included length of initial training program, size of training program, amount of turnover in the organization, the extent to which participants can recall their emotions during training, how useful training was for the participants, how many jobs participants have held since the training program in mind, the time since the training program, and how integral participants feel emotions are to the job they do. The length of training programs was measured in days, with an 
average length of training reported as 20.79 days $(S D=60.87)$, and positively skewed. The size of the training program was an average of 7.98 individuals $(S D=6.01)$, and was also positively skewed. On a 10-point scale with 1 being not very much and 10 being quite a bit, the mean turnover reported was 3.96 out of $10(S D=2.80)$, which is relatively low. When asked how well they could remember the emotions experienced during their training program, participants thought they could recall them relatively well. Participants reported an average of 6.36 out of $10(S D=2.91)$ when asked this question. The average usefulness of the training program was 7.08 out of $10(S D=2.50)$. Thus, participants' training programs were highly useful. Participants reported an average of 2.27 jobs since the training program $(S D=1.69)$, and an average of 1246.02 days, or just less than three and a half years, since the training program in mind $(S D=1996.94)$. Although some participants have been in their current position for quite a while since completing their training program, if their emotional experience was extreme, either positive or negative, they will likely be able to recall their initial emotions. Participants reported an average of 8.41 out of $10(S D=1.84)$ when asked how important emotions are to the job an individual does. Thus, participants viewed emotions as highly important to the job they do.

\section{Procedures}

Participants were distributed an invitation via email with a link to the online survey by means of a snowball sample. Due to the difficulty of accessing a large number of working professionals in a limited amount of time, a snowball sample was used. Initially, a few individuals from large organizations were contacted, who then were asked to pass the survey link on to their own networks. This way, a larger population across a 
larger geographic distance was reached, which benefited the study. These professionals were asked to pass along the survey link to their co-workers and other professional contacts after they had taken the survey themselves. Other means of recruitment came from social media sites such as Facebook, Twitter, and LinkedIn, as well as email listservs like CRTNET. The survey link was posted on the researcher's personal social media accounts with an invitation to take the survey in the hopes of recruiting more participants.

Participants were asked to report the number of jobs they have had in the past, as well as the number of training programs they have completed. Other questions inquired about their education level and how much time has elapsed since this training program took place. Participants were asked to keep in mind the initial training program they completed and their time in that position. Survey questions were asked about trainer likeability, clear definition of tasks, employee socialization, employee satisfaction, and employee intent to leave, as well as the different positive and negative emotions experienced during the training.

Participants were asked to think of the most recent job where they completed some kind of training program before beginning their position. They were instructed to keep this specific training program in mind while answering the survey questions to follow. One downfall of this method is that some individuals may not recall the specifics of their training programs because it is not fresh in their minds. However, if the training program made a big impact on them, they will remember years or even decades later. The way an individual remembers the training program will have an effect long-term. There 
was some degree of recall bias, due to a retrospective manner of asking about training. However, there is not a way around this.

\section{Measurement}

\section{Survey Instrument}

The survey instrument was comprised of a mix of items developed for purposes of the current study and questions taken from previous scales. Items measuring job satisfaction, employee intent to leave, employee socialization, and trainer likeability and clarity allowed participants to respond on a 5-point Likert scale ranging from 1 (Strongly Disagree) to 5 (Strongly Agree). The 20 items measuring positive and negative emotional experience allowed participants to respond on a Likert-type scale ranging from 1 (did not experience this emotion at all) to 5 (a great deal of this emotion was experienced). Instead, participants were asked the extent to which they can recall the emotions they experienced during their training program and how useful they believed this training to be. This study sought to find if the initial training program is effective. Finally, participants were asked to provide individual demographic information, allowing the researcher to account for individual participant characteristics. See the Appendix for the complete survey instrument.

\section{Validity and Reliability}

During the scale development stage, it is important that survey items be subjected to factor analysis in order to test for validity and reliability of each item. Factor analysis is used to identify clusters of items or confirm the suspected groupings of items and underlying constructs. After data collection, a series of exploratory factor analysis (EFA) procedures employed principal components extraction. Varimax rotation was employed 
because rotating factor solutions allows for more interpretable results (Mertler \& Vannatta, 2005). Initially, the factor analysis procedure checked Kaiser-Meyer-Olkin (KMO) measure of sampling accuracy and Bartlett's test of sphericity to determine if the data meet the assumptions of factor analysis. To meet the assumptions of factor analysis, the KMO coefficient should be in the high $.8 \mathrm{~s}$ and the Bartlett's test should be significant (Mertler \& Vannatta, 2005; Meyers et al., 2006). For the current study, these were the standards used.

Factor structure of each scale was determined by analyzing several criteria for selecting items that cluster together into factors. Items were dropped if they did not meet the $60 / 40$ criteria for factor loadings; that is, the primary loading for an item should be at least .60 and no secondary loading should be .40 or higher. Eigenvalue scores and a visual inspection of the scree plot from the rotated factor matrix helped determine which factors would be retained. Upon factor analysis procedures, the item with the lowest primary factor loading that did not meet the $60 / 40$ criteria was removed from the solution and new EFA procedures were conducted until all items in each scale passed this test. According to Kaiser's rule, only factors with eigenvalue scores greater than 1 should be retained (Mertler \& Vannatta, 2005). Again, these were the standards the present study was guided by.

\section{Emotions Scale}

The survey participants were asked to keep the same training program in mind for the questions regarding positive and negative emotions felt during that training program. This scale was created entirely by the researcher for the use of this study. Eleven of the 20 emotions were negatively valenced, such as "afraid" and "sad," and the remaining 
nine emotions were positively valenced, including "happy" and "proud." The goal was to keep the positive and negative emotions somewhat balanced.

Emotional experience is the independent variable in this study. Emotional experience refers to which separate emotions a new employee feels during initial training programs. This emotional experience can consist of one solitary positive or negative emotion, but is more oftentimes a combination of several emotions. For the 20 -item emotions scale, a factor analysis procedure via principle components extraction with varimax rotation was calculated while forcing a two-factor solution. This strategy did not work because the two factors did not explain enough of the variance. Then, we tried one more and one less factor. When three factors were forced, more items were retained per factor. With these three factors, the loadings were much better, though the factors were not correlated. The three factors consisted of positive, negative, and somewhat neutral emotions, though these "neutral" emotions seemed somewhat negative. For the purpose of this study, these negative-leaning emotions will be referred to as "neutral" for clarity. The final factor analysis procedure produced an acceptable three-factor solution. Both the KMO measure (.794) and Bartlett's test $\left[\chi^{2}=1356.669(190), p<.001\right]$ were acceptable. The two-factor solution, consisting of three items apiece, collectively explained $64.103 \%$ of the variance. All three factors had good reliabilities. Factor one, the positive emotions, included excited, passionate, happy, proud, joyful, eager, and interested. Factor two, the negative emotions, included sad, disappointed, angry, and hurt. The third and final factor, or the somewhat neutral emotions, included unsure, afraid, nervous, and concerned. A few items were still lost, however, after factor analysis procedures. The emotions surprised, lonely, content, confused, and frustrated were removed, in that order, due to 
their low factor loadings. In the end, 15 items were retained in a three-factor solution. Each of the 15 items remaining had factor loadings meeting the 60/40 criteria. Higher mean scores meant a more favorable emotional reaction to the training program, which were used to answer Hypotheses 1 and 3. Lower mean scores denoted a less favorable emotional reaction to the training and were used to answer Hypotheses 2 and 4.

Interestingly, somewhat neutral emotions emerged, but they were not used to answer any Hypotheses. All emotions, positive and negative, were used to answer the Research Question. See Table 1 for the factor loadings. 
Table 1

Factor Loadings for Emotions Scale

\begin{tabular}{|c|c|c|c|}
\hline Survey Item & Positive & Negative & Neutral \\
\hline I felt excited. & .806 & -.111 & .159 \\
\hline I felt passionate. & .803 & .028 & -.034 \\
\hline I felt happy. & .792 & -.186 & -.064 \\
\hline I felt joyful. & .732 & -.003 & -.013 \\
\hline I felt eager. & .715 & -.028 & .142 \\
\hline I felt interested. & .647 & -.266 & .140 \\
\hline I felt proud. & .634 & .085 & .019 \\
\hline I felt sad. & -.054 & .906 & .115 \\
\hline I felt disappointed. & -.134 & .805 & .161 \\
\hline I felt angry. & -.064 & .787 & .127 \\
\hline I felt hurt. & -.007 & .778 & .206 \\
\hline I felt unsure. & .013 & .114 & .897 \\
\hline I felt afraid. & .069 & .280 & .813 \\
\hline I felt nervous. & .254 & .030 & .762 \\
\hline I felt concerned. & -.064 & .223 & .742 \\
\hline Eigenvalue & 3.888 & 2.961 & 2.766 \\
\hline$\%$ of Variance & 25.921 & 19.741 & 18.441 \\
\hline Cronbach's Alpha & .858 & .838 & .844 \\
\hline
\end{tabular}

Note. Underlined factor coefficients show acceptable factor loadings for the corresponding items and factors.

\section{Job Satisfaction Scale}

One of the dependent variables being measured in this study was job satisfaction. Satisfaction refers to how much the employee likes their job or position within the organization (Arslan \& Acar, 2013). Although in organizational communication the Job Descriptive Index, or JDI (Smith, Kendall, \& Hulin, 1969), is often considered the standard in measuring job satisfaction, this scale does not operationalize job satisfaction in the same way as the present study. The JDI asks "Yes/No" questions about the diversity of the workforce, pay, supervision, and other experiences within the organization. For the purpose of the current study, the JDI was too broad a measurement 
of satisfaction. The Job Satisfaction Survey, or JSS (Astrauskaite, Vailkevicius, \& Perminas, 2011), however, included many items that delve into the issues the current study seeks to undercover. The JSS was originally created and presented by Spector (1997). The JSS nature of work (4 items) and communication (4 items) subscales were used in their entirety. These subscales measured the dimensions of satisfaction appropriate for the present study. Survey items from the JSS include, "I like doing the things I do at work" and "Communications seem good within this organization," as well as several others. The JSS was chosen because this instrument provides sufficient reliability, validity through a CFA. The alpha for the nature of work subscale was .78 , and the communication subscale was .71. Multiple dimensions emerged, hence the subscales of communication and nature of work that were used.

Eight items were taken from the JDI (1969), from the nature of work (4 items) and communication (4 items) subscales, which measure job satisfaction. Five self-made items were added as well. Through factor analysis procedures, two factors were forced, and five items were removed due to poor primary factor loadings. Factor one was comprised of the nature of work subscale (6 items), and factor two was comprised of the communication subscale (4 items). Both the KMO measure (.896) and Bartlett's test $\left[\chi^{2}=\right.$ $803.103(55), p<.001]$ were acceptable. The two-factor solution, consisting of nature of work (6 items), and communication ( 3 items), collectively explained $69.835 \%$ of the variance. The first factor explained $47.344 \%$ of the variance with a 4.734 eigenvalue, and the second factor explained $22.492 \%$ of the variance with a 2.249 eigenvalue. The final two-factor solution produced an overall alpha coefficient reliability of .89 for the scale, 
with reliabilities for the subscales as follows: nature of work $(\alpha=.92)$, and communication $(\alpha=.77)$. See Table 2 for the factor loadings.

Table 2

Factor Loadings for Job Satisfaction Scale

\begin{tabular}{|c|c|c|}
\hline Survey Item & $\begin{array}{l}\text { Nature of } \\
\text { work }\end{array}$ & Communication \\
\hline I feel a sense of pride in doing my job. & $\underline{.895}$ & .068 \\
\hline My job is enjoyable. & .861 & .237 \\
\hline I am satisfied with my job. & .841 & .192 \\
\hline I like doing the things I do at work. & .833 & .172 \\
\hline I am not happy with my job. [Recoded] & .758 & .282 \\
\hline I sometimes feel my job is meaningless. [Recoded] & .694 & .262 \\
\hline $\begin{array}{l}\text { I often feel that I do not know what is going on with the } \\
\text { organization. [Recoded] }\end{array}$ & .136 & .827 \\
\hline Work assignments are not fully explained. [Recoded] & .142 & .822 \\
\hline $\begin{array}{l}\text { The goals of this organization are not clear to me. } \\
\text { [Recoded] }\end{array}$ & .182 & .783 \\
\hline Eigenvalue & 4.734 & 2.249 \\
\hline$\%$ of Variance & 47.344 & 22.492 \\
\hline Cronbach's Alpha & .924 & .770 \\
\hline
\end{tabular}

Note. Underlined factor coefficients show acceptable factor loadings for the corresponding items and factors.

\section{Intent to Leave Scale}

Intent to leave is an employee's commitment to the organization, or the organization's ability to keep employees in the organization. For the intent to leave variable, survey questions were adapted from both O'Reilly and Chatman's (1986) and Rosin and Korabik's (1991) intent to leave scales. The 11 adapted items from O'Reilly 
and Chatman's scale were those that delved into employee commitment to the organization, as the present study sought to measure this. Items such as, "I am proud to tell others that I am part of this organization" and "I feel a sense of 'ownership' for this organization rather than being just an employee" were used. O'Reilly and Chatman's items that were not used asked about personal values and those of the organization, which are not being measured in the current study. Initially, the O'Reilly and Chatman scale was measured on a 7-point scale where participants marked the extent to which they agreed or disagreed to each statement. Factor analysis was performed on this scale, and three factors emerged for the 11 total items, with $(\alpha=.86)$. Previous reliability coefficient has been reported at $(\alpha=.82)$, with good reliability, found through a canonical correlation (Rosin \& Korabik). The four-item intent to leave scale from Rosin and Korabik was used in its entirety. Rosin and Korabik's items included questions such as, "I am actually planning to leave my job within the next six months" and "I am actively searching for another job right now." In the original survey, participants answered "yes," "no," or "not sure" to each of the four questions. For the purpose of the current study, these survey items were slightly rephrased so that they could be answered using a Likert scale.

The intent to leave scale began with 16 items and ended up with 13 total items after factor analysis procedures. Two factors were forced, and three items were removed due to poor primary factor loadings. Factor one was comprised of four items, factor two was comprised of four items, factor three was comprised of three items, and the final factor included just two items. The fourth factor ( 2 items) was ultimately removed due to poor factor loadings. Thus, the final scale included three factors. Factor one included an 
eigenvalue of 3.009, factor two had an eigenvalue of 2.603 , and the final factor had an eigenvalue of 2.372 , with an overall scale alpha of .513 explaining $72.577 \%$ of the variance. Both the KMO measure (.853) and Bartlett's test $\left[\chi^{2}=1167.513(120), p<\right.$ $.001]$ were acceptable. The final three-factor solution produced an overall alpha coefficient reliability of .513 for the scale, with reliabilities for the three subscales as follows; factor one $(\alpha=.89)$, factor two $(\alpha=.81)$, and factor three $(\alpha=.85)$. See Table 3 for the factor loadings.

Table 3

Factor Loadings for Intent to Leave Scale

\begin{tabular}{|c|c|c|c|}
\hline Survey Item & Values & Volunteer & Planning \\
\hline What this organization stands for is important to me. & .862 & .241 & -.219 \\
\hline I am proud to tell others I am a part of this organization. & .839 & .157 & -.269 \\
\hline $\begin{array}{l}\text { I feel a sense of ownership for this org. rather than being } \\
\text { just an employee. }\end{array}$ & .775 & .241 & -.273 \\
\hline $\begin{array}{l}\text { My attachment to this organization is primarily based on } \\
\text { the similarity of my values and those represented by the } \\
\text { organization. }\end{array}$ & .726 & .247 & -.233 \\
\hline $\begin{array}{l}\text { I attend functions that are not required, but that help the } \\
\text { organization's image. }\end{array}$ & .362 & .807 & -.047 \\
\hline $\begin{array}{l}\text { I participate in planning and organizing social events at } \\
\text { work. }\end{array}$ & .053 & .783 & -.148 \\
\hline I volunteer for tasks that are not required. & 167 & .778 & -.151 \\
\hline I make suggestions to improve the organization. & .242 & .684 & -.085 \\
\hline I am actively searching for another job right now. & -.237 & -.150 & .886 \\
\hline $\begin{array}{l}\text { I am actually planning to leave my job within the next } \\
\text { six months. }\end{array}$ & .214 & -.196 & .880 \\
\hline I have had thoughts of leaving my job. & -.332 & -.054 & -.713 \\
\hline Eigenvalue & 3.009 & 2.603 & 2.372 \\
\hline$\%$ of Variance & 27.352 & 23.664 & 21.561 \\
\hline Cronbach's Alpha & .891 & .810 & .854 \\
\hline
\end{tabular}

Note. Underlined factor coefficients show acceptable factor loadings for the corresponding items and factors. 


\section{Socialization Scale}

Employee socialization is the process of a new employee becoming comfortable in their new organization. The socialization scale used was adapted from Chao et al.'s (1994) organizational socialization scales. Three dimensions of their scale, history (5 items), politics (6 items), and performance proficiency (5 items), were taken and used in their entirety, for a total of 16 items. Items such as, "I am not familiar with the organization's customs, rituals, ceremonies, and celebrations" and "I know the organization's long-held traditions" were used. Other dimensions of the Chao et al. scales did not measure socialization in the way this variable was conceptually defined for the present study. Originally, the scale items were ordered randomly, and participants were asked to rate their agreement or disagreement on a 5-point Likert scale. An EFA was conducted, and six factors were extracted, accounting for $58.1 \%$ of the variance. The reliability of all scale dimensions as measured by Cronbach's alpha was found to be acceptable. From 1988 to 1991, alphas for the history subscale ranged from .82 to .85 , politics subscale ranged from .79 to .81 , and performance proficiency ranged from .78 to .82 .

Ultimately, through factor analysis procedures, four items were eliminated from the socialization scale because they had poor primary factor loadings. Three factors were forced based on Chao's (1994) three-factor scale including items of history, performance proficiency, and politics, using rotated matrix factor loadings. The final factor analysis procedure produced an acceptable three-factor solution. Both the KMO measure (.884) and Bartlett's test $\left[\chi^{2}=788.407(66), p<.001\right]$ were acceptable. The three-factor solution, consisting of history ( 5 items), performance proficiency (4 items), and politics 
(3 items), collectively explained $69.544 \%$ of the variance. The first factor explained $27.690 \%$ of the variance with a 3.323 eigenvalue, the second factor explained $24.722 \%$ of the variance with a 2.967 eigenvalue, and the third factor explained $17.132 \%$ of the variance with a 2.056 eigenvalue. The final three-factor solution produced an overall alpha coefficient reliability of .89 for the scale, with reliabilities for the subscales as follows: history $(\alpha=.87)$, performance proficiency $(\alpha=.87)$, and politics $(\alpha=.66)$. See Table 4 for the factor loadings.

\section{Trainer Clarity and Likeability}

Trainer clarity and likeability were held constant while running regression models in order to focus on the significance of the emotional experience during new employee training. Trainer likeability refers to how likeable the trainer is to the new employees in the training program, and trainer clarity is how clear and defined the trainer made the new employees' tasks for them. Trainer clarity is an important variable to consider when delivering material, as it influences employees' ability to understand the expectations and other job-related information (Simonds, 1997). Liking your trainer as a person can add a halo effect to the training and cloud your perceptions of the training as a whole. While the trainer is an artifact of any training program, trainer likeability and clarity were held constant in order to reduce confusion about which variables influence job satisfaction, employee intent to leave, and perceptions of socialization.

Trainer clarity was adapted from Simonds' (1997) instructor clarity scale. The majority of this scale's items were able to be adapted to measure trainer clarity by rewording the items. Items that mentioned exams and quizzes were not applicable to trainer clarity, and thus were removed from the present scale. Fourteen total items were 
adapted and used. These items included, "My trainer stressed important points in training" and "My trainer communicated organization processes and expectations clearly." Both factor analysis and Cronbach's alpha were run to determine dimensionality and reliability of the instructor clarity scale. The overall reliability for the Teacher Clarity Report was .93 , with a subscale reliability of .88 for content clarity and .88 for process clarity. Factor analysis revealed the two factors accounted for $54.2 \%$ of the variance. Results of these analyses indicated that teacher clarity is a unidimensional measure. 
Table 4

Factor Loadings for Socialization Scale

\begin{tabular}{|c|c|c|c|}
\hline Survey Item & History & Proficiency & Politics \\
\hline I am familiar with the history of my organization. & .803 & .152 & .285 \\
\hline $\begin{array}{l}\text { I know very little about the history behind my work } \\
\text { group/department. [Recoded] }\end{array}$ & .803 & .170 & .060 \\
\hline I know the organization's long-held traditions. & .777 & .187 & .242 \\
\hline $\begin{array}{l}\text { I am not familiar with the organization's customs, } \\
\text { rituals, ceremonies, and celebrations. [Recoded] }\end{array}$ & .744 & .243 & -.053 \\
\hline $\begin{array}{l}\text { I would be a good resource in describing the } \\
\text { background of my work group/dept. }\end{array}$ & .712 & .310 & .372 \\
\hline $\begin{array}{l}\text { I have not fully developed the appropriate skills and } \\
\text { abilities to successfully perform my job. [Recoded] }\end{array}$ & .276 & .838 & .032 \\
\hline I have mastered the tasks of my job. & .159 & .831 & .272 \\
\hline I understand what all the duties of my job entail. & .165 & .797 & .232 \\
\hline $\begin{array}{l}\text { I have learned how to successfully perform my job in an } \\
\text { efficient manner }\end{array}$ & .343 & .751 & .257 \\
\hline $\begin{array}{l}\text { I have a good understanding of the motives behind the } \\
\text { actions of other people in the organization. }\end{array}$ & .098 & .091 & .771 \\
\hline $\begin{array}{l}\text { I can identify the people in the organization who are } \\
\text { most important in getting the work done. }\end{array}$ & .078 & .288 & .756 \\
\hline \multirow{4}{*}{$\begin{array}{l}\text { I know who the most influential people are in my } \\
\text { organization. }\end{array}$} & .326 & .199 & .640 \\
\hline & 3.323 & 2.967 & 2.056 \\
\hline & 27.690 & 24.722 & 17.132 \\
\hline & .876 & .879 & .663 \\
\hline
\end{tabular}

Note. Underlined factor coefficients show acceptable factor loadings for the corresponding items and factors.

An instructor likeability scale created by Abrantes, Seabra, and Lages (2007) was adapted to measure trainer likeability for the present study. Three items applied to trainer likeability, and thus were used for the present study. Items that were chosen from Abrantes et al.'s scale include, "I liked my trainer as a person," "My trainer seems to have an equal concern for all trainees," and "My trainer was actively helpful when trainees had difficulty." Abrantes et al. used a confirmatory factor analysis (CFA) to 
assess the validity of the measure, revealing a good model fit. Reliability alphas ranged from .76 to .83 . Several questions were written for the present study, about trainer likeability were added to lengthen the scale. These items include, "I would enjoy working with my trainer again on future tasks" and "I enjoyed spending time at work with my trainer." Trainer Clarity went from 16 to 10 total items after factor analysis procedures, with one factor. The one factor solution included 10 items with an eigenvalue of 6.067, and accounted for $60.668 \%$ of the variance $(\alpha=.92)$. The trainer likeability scale ( 9 items) fit into one factor with a 6.438 eigenvalue and accounts for $71.537 \%$ of the total variance $(\alpha=.94)$. See Tables 5 and 6 for the factor loadings.

\section{Data Analysis}

In order to measure the variables of emotional experience, job satisfaction, employee intent to leave, socialization, trainer likeability, and trainer clarity, a factor analysis was run to test for a priori underlying constructs within the scale. The factor analysis tested for validity and dimensionality of the survey instrument, while the reliability of the instrument was determined using Cronbach's alpha coefficient of reliability. 
Table 5

Factor Loadings for Trainer Clarity Scale

\begin{tabular}{|c|c|c|}
\hline Survey Item & Materials & Directions \\
\hline $\begin{array}{l}\text { My trainer clearly explained the objectives for the content being } \\
\text { presented. }\end{array}$ & .882 & .068 \\
\hline My trainer gave summaries when presenting content. & .841 & .237 \\
\hline My trainer stayed on topic. & .799 & .192 \\
\hline My trainer gave previews of material to be covered in training. & .766 & .172 \\
\hline My trainer stressed important points in training. & .755 & .282 \\
\hline My trainer was clear when presenting content. & .733 & .262 \\
\hline My trainer defined major/new concepts. & .715 & .827 \\
\hline My trainer pointed out practical applications for training. & .707 & .822 \\
\hline $\begin{array}{l}\text { My trainer communicated organization processes and } \\
\text { expectations clearly. }\end{array}$ & .701 & .783 \\
\hline My trainer described work tasks and how they should be done. & .671 & .320 \\
\hline It is clear to me what I need to do at work. & .179 & .855 \\
\hline I have not received directions as to which tasks to complete. & .102 & .839 \\
\hline Eigenvalue & 5.812 & 1.865 \\
\hline$\%$ of Variance & 48.434 & 15.540 \\
\hline Cronbach's Alpha & .926 & .673 \\
\hline
\end{tabular}

Note. Underlined factor coefficients show acceptable factor loadings for the corresponding items and factors.

The closed-ended survey questions used in the present study were subjected to computer analysis. Using SPSS, a series of hierarchical multiple linear regressions were conducted to test each hypothesis and the single research question. Multiple linear regression analyses were done to reveal relationships among the variables explored in the present study. Multiple linear regressions control for the predictor variables measured in the study in order to isolate the ability of a single predictor variable in order to predict a significant amount of variance in the dependent variable. In other words, it has already 
been determined that trainer likeability and clarity have an effect on new hires. For the present study, these variables were held constant in order to isolate the emotional responses of the new employees and to test their long-term effects on job satisfaction, intent to leave, and socialization. The level of significance or alpha was set to .05 for all statistical tests in accordance with common practices. No adjustments were made to alpha for the statistical procedures employed in the study.

Table 6

Factor Loadings for Trainer Likeability Scale

Survey Item Likeability

I like my trainer as a person. $\underline{.924}$

I enjoyed spending time at work with my trainer.

$\underline{.915}$

My trainer was likeable. $\underline{.902}$

I would enjoy working with my trainer again on future tasks. $\underline{.882}$

My trainer was actively helpful when trainees had difficulty. .858

My trainer seemed to have an equal concern for all trainees.

I would rather not work with my trainer outside of the training program. .819

I did not find my trainer to be pleasant. $\underline{800}$

I do not find my trainer to be pleasant.

$\begin{array}{rr}\text { Eigenvalue } & 6.438 \\ \text { \% of Variance } & 71.537\end{array}$

Cronbach's Alpha .945

Note. Underlined factor coefficients show acceptable factor loadings for the corresponding items and factors.

The predictor variables identified in $\mathrm{H} 1, \mathrm{H} 2, \mathrm{H} 3$, and $\mathrm{H} 4$, as well as the RQ, consist of the positive and negative emotions that the professionals felt during their 
training programs. The outcome variables in each of the hypotheses and research questions were job satisfaction, employee intent to leave, and socialization. Hierarchical multiple linear regression procedures were calculated to answer the two hypotheses and research question posed in this study. The regression models investigated whether or not a new employee's job satisfaction, employee intent to leave, and socialization can be predicted by the positive and negative emotions experienced during initial training periods after controlling for trainer likeability and trainer clarity. Therefore, a hierarchical multiple linear regression analysis was conducted to predict the amount of variance in each outcome variable explained by the predictor and control variables.

Online surveys typically receive lower response rates than in-person surveys (Watt, 1999) because of the lessened social pressure to respond to an email than to a live person (Dillman, 2000). Several actions were taken with the hopes of increasing responses to the online survey in the present study, including keeping the survey rather brief, sending reminder e-mails, and of course, ensuring confidentiality of responses (Tuten, Urban, \& Bosnjak, 2002). A non-response bias analysis was conducted to identify possible sources of bias among responders versus non-responders, since the overall survey response rate was so low, as suggested by Bose (2001). Differences were tested between early and late responders, as later respondents are assumed to be more similar to non-respondents than to earlier respondents (Bose, 2001). This was done by running independent samples $t$-tests comparing means for the first 40 and last 40 survey respondents. Only two statistically significant differences were found between the early and late responders out of the eight total subscales for the dependent variables. This analysis suggests that the sample was relatively free of non-response bias. Also, it is 
likely that the first participants to take the survey were the first people sent the link, whereas the later participants were a result of soliciting additional groups of participants to increase sample size. Due to the snowball sample and the low response rate so close to the time of closing the survey, the researcher reached out to initial participants to remind them to forward the link to any networks who may be interested, as well as to any other connections who had not been sent the link before. Since the majority of the participants who were sent the survey just before it closed were seeing it for the first time, it is logical that there is not a significant difference between the early and late participants. See Table 7 for the $t$-test results.

\section{Table 7}

Independent Samples t-test Comparing Early and Late Responders

\begin{tabular}{|c|c|c|c|}
\hline Scale & $t$ & $d f$ & $p$ \\
\hline Socialization/History & -1.529 & 78 & .130 \\
\hline Socialization/Politics & -1.273 & 78 & .207 \\
\hline Socialization/Performance Proficiency & .978 & 78 & .331 \\
\hline Intent to Leave/Values & 2.658 & 1.683 & $.010^{*}$ \\
\hline Intent to Leave/Volunteer & 1.387 & 74 & .170 \\
\hline Intent to Leave/Planning & 1.999 & 74 & $.049 *$ \\
\hline Satisfaction/Nature of Work & 3.036 & 63.763 & $.003^{*}$ \\
\hline Satisfaction/Communication & -.257 & 74 & .798 \\
\hline
\end{tabular}

Note: Asterisks represent significant values of $p<.05$. The table compares the first 40 to the last 40 survey respondents. 


\section{CHAPTER III}

\section{RESULTS}

This chapter will first describe how the statistical tests employed were set up and then report the results of those tests. Missing cases were excluded pairwise in each of the multiple linear regressions so as to retain as much useable data as possible. Sequential block entry was employed to regress all predictor and control variables onto the dependent variable in two steps. Specifically, both control variables, trainer clarity and trainer likeability, were entered in the first step, while all predictor variables were entered into the second step, as there was no strong theoretical rationale to enter these variables in a particular order. Significance levels for alpha were set at .05.

\section{Job Satisfaction}

In order to interpret Hypotheses 1 and 2, hierarchical multiple linear regressions were run. The dependent variable in these hypotheses was job satisfaction, and the control variables were clarity and likeability. The likeability and clarity of the trainer have some effect on the new hires during training, but the present study sought to examine the effects of the emotional experience of the new employees, without considering the trainer. The regression model investigated if a new employee's job satisfaction could be predicted by increased experience of positive emotions and decreased by the increase of negative emotions during training, after controlling for trainer likeability and trainer clarity. Therefore, hierarchical multiple linear regression analyses were conducted to predict Job Satisfaction from the positive emotions scale. 
Results of the hierarchical multiple linear regression analysis indicated that $10.9 \%$ of the variance in Job Satisfaction/Nature of Work could be predicted by the control variable, trainer clarity, $R_{a d j}^{2}=.093, F(2,114)=6.950, p<.01$. In the second step, after again controlling for trainer likeability and trainer clarity, the global predictor variables resulted in a significant change, uniquely accounting for an additional $28.9 \%$ of the variance, $\Delta F(3,111)=17.723, p<.01$. Overall, the model accounted for $39.7 \%$ of the variance in Job Satisfaction/Nature of Work, $R_{a d j}^{2}=.370, F(5,111)=14.637, p<.01$. Thus, the significant results of the regression procedure indicated that the linear combination of the predictor variables (emotions scales) was able to account for a significant amount of variance in the dependent variable, after statistically controlling for trainer likeability and trainer clarity.

Regression coefficients indicated that Emotions Positive, $\beta=.459, t=5.785, p<$ .01 , and Emotions Negative, $\beta=-.249, t=-3.090, p<.01$, emerged as the only significant predictors when all variables were in the model. The squared part correlations revealed that Emotions Positive uniquely predicted $18.1 \%$ of the variance in Job Satisfaction/Nature of Work, and Emotions Negative uniquely predicted $5.19 \%$ of the variance.

For the Job Satisfaction/Communication scale, the results of the hierarchical multiple linear regression analysis indicated that $22.5 \%$ of the variance in $J o b$ Satisfaction/Communication could be predicted by control variables, $R^{2}{ }_{a d j}=.212, F(2$, $114)=16.570, p<.01$. In the second step, after controlling for trainer clarity and likeability, the predictor variables (emotions scales) resulted in a significant change, uniquely accounting for an additional $9.3 \%$ of the variance, $\Delta F(3,111)=5.058, p<.01$. 
Overall, the model accounted for $31.8 \%$ of the variance in $J o b$

Satisfaction/Communication, $R_{a d j}^{2}=.288, F(5,111)=10.370, p<.01$. Thus, the significant results of the regression procedure indicated that the combination of the emotion scales was able to account for a significant amount of variance in the dependent variable, after statistically controlling for trainer clarity and likeability. Descriptive statistics for the predictor and dependent variables in the final model can be found in Table 8.

Table 8

Beta Weights for Job Satisfaction/Nature of Work Model

\begin{tabular}{|c|c|c|c|c|c|c|c|}
\hline \multirow[b]{2}{*}{ Variable } & & \multicolumn{3}{|c|}{ First Block } & \multicolumn{3}{|c|}{ Second Block } \\
\hline & & $B$ & $S E B$ & $\square$ & $B$ & $S E B$ & $\square$ \\
\hline Trainer Likeability & & .081 & .115 & .081 & .010 & .097 & .010 \\
\hline Trainer Clarity & & .350 & .149 & $.271^{*}$ & .194 & .126 & .151 \\
\hline Emotions Positive & & & & & .463 & .080 & $.459 *$ \\
\hline Emotions Negative & & & & & -.286 & .092 & $-.249 *$ \\
\hline Emotions Neutral & & & & & -.070 & .065 & -.087 \\
\hline & $R^{2}$ & & . 109 & & & 397 & \\
\hline & $R_{a d j}^{2}$ & & 093 & & & .370 & \\
\hline & $\square R^{2}$ & & .109 & & & .289 & \\
\hline & $F$ & & 6.950 & & & 14.637 & \\
\hline
\end{tabular}

Note. An * indicates a unique significant predictor variable at $p<.05$.

Analysis of regression coefficients indicated that Trainer Clarity, $\beta=.478, t=$ 4.589, $p<.01$, and Emotions Positive, $\beta=.478, t=4.589, p<.01$, emerged as the only significant predictors when all variables were in the model. The squared part correlations revealed that Trainer Clarity uniquely predicted $12.9 \%$ of the variance in $J o b$ Satisfaction/Communication, Emotions Positive uniquely predicted $6.0 \%$ of the variance, and Emotions Neutral uniquely predicted $4.40 \%$ of the variance. 
In sum, Emotions Positive and Emotions Negative predicted significant unique variance in Job Satisfaction. Thus, the more positive emotions a new employee experiences in an initial training program, the more satisfied they would feel about their job. The same is true for the reverse. The more negative emotions a new employee experiences during their initial training program, the less satisfied they will be with their job, thus supporting Hypotheses 1 and 2. In addition, since Trainer Clarity emerged as strong predictors of Job Satisfaction in the final model, organizations in the process of creating new training programs or improving existing ones should focus not only on the emotional experience of their new employees, but also on the clarity of the trainer who is implementing the program. Beta weights for the final regression model can be found in Table 9.

\section{Intent to Leave}

The regression models for Hypotheses 3 and 4 (Intent to Leave) investigated if an employee's intent to leave the organization could be predicted by increased experience of positive emotions and decreased by the increase of negative emotions during training, after controlling for trainer likeability and trainer clarity. Therefore, hierarchical multiple linear regression analyses were conducted to predict Intent to Leave from the positive, and negative emotions scales. 
Table 9

Beta Weights for Job Satisfaction/Communication Model

\begin{tabular}{|c|c|c|c|c|c|c|}
\hline \multirow[b]{2}{*}{ Variable } & \multicolumn{3}{|c|}{ First Block } & \multicolumn{3}{|c|}{ Second Block } \\
\hline & $B$ & $S E B$ & $\square$ & $B$ & $S E B$ & $\square$ \\
\hline Trainer Likeability & -.105 & .105 & -.108 & -.148 & .101 & -.152 \\
\hline Trainer Clarity & .677 & .136 & $.537 *$ & .603 & .131 & $.478 *$ \\
\hline Emotions Positive & & & & .260 & .083 & $.264 *$ \\
\hline Emotions Negative & & & & .020 & .096 & .018 \\
\hline Emotions Neutral & & & & -.180 & .067 & $-.230 *$ \\
\hline$R^{2}$ & & .225 & & & $.31 \xi$ & \\
\hline$R_{a d j}^{2}$ & & .212 & & & .288 & \\
\hline$\square R^{2}$ & & .225 & & & .093 & \\
\hline$F$ & & 16.570 & & & 10.370 & \\
\hline
\end{tabular}

Note. An * indicates a unique significant predictor variable at $p<.05$.

Results of the hierarchical multiple linear regression analysis indicated that $14.5 \%$ of the variance in Intent to Leave/Values could be predicted by the control variable, trainer clarity, $R_{a d j}^{2}=.130, F(2,114)=9.659, p<.01$. In the second step, after again controlling for trainer likeability and trainer clarity, the predictor variables resulted in a significant change, uniquely accounting for an additional $22.6 \%$ of the variance, $\Delta F(3$, $111)=13.323, p<.01$. Overall, the model accounted for $37.1 \%$ of the variance in Intent to Leave/Values, $R_{\text {adj }}^{2}=.343, F(5,111)=13.110, p<.01$. Thus, the significant results of the regression procedure indicated that the linear combination of the predictor variables (emotions scales) was able to account for a significant amount of variance in the dependent variable, after statistically controlling for trainer likeability and trainer clarity. Analysis of regression coefficients indicated that Emotions Positive, $\beta=.456, t=$ $5.626, p<.01$, emerged as the only significant predictor when all variables were in the model. The squared part correlations revealed that Emotions Positive uniquely predicted $17.8 \%$ of the variance for Intent to Leave/Values. 
The hierarchical multiple linear regression analysis for the second subscale of the Intent to Leave scale indicated that $4.40 \%$ of the variance in Intent to Leave/Volunteer could be predicted by control variables, $R_{a d j}^{2}=.027, F(2,114)=2.636, p<.01$. In the second step, after controlling for trainer clarity and likeability, the predictor variables (emotions scales) resulted in a significant change, uniquely accounting for an additional $16.6 \%$ of the variance, $\Delta F(3,111)=7.765, p<.01$. Overall, the model accounted for $21.0 \%$ of the variance in Intent to Leave/Volunteer, $R_{a d j}^{2}=.174, F(5,111)=5.901, p<$ .01 . Thus, the significant results of the regression procedure indicated that the combination of the emotion scales was able to account for a significant amount of variance in the dependent variable, after statistically controlling for trainer clarity and likeability. Descriptive statistics for the predictor and dependent variables in the final model can be found in Table 10 .

Table 10

Beta Weights for Intent to Leave/Values Model

\begin{tabular}{|c|c|c|c|c|c|c|c|}
\hline \multirow[b]{2}{*}{ Variable } & & \multicolumn{3}{|c|}{ First Block } & \multicolumn{3}{|c|}{ Second Block } \\
\hline & & $B$ & $S E B$ & $\square$ & $B$ & $S E B$ & $\square$ \\
\hline Trainer Likeability & & .270 & .123 & .248 & .202 & .108 & $.185^{*}$ \\
\hline Trainer Clarity & & .239 & .160 & .170 & .084 & .141 & .059 \\
\hline Emotions Positive & & & & & .503 & .089 & $.456^{*}$ \\
\hline Emotions Negative & & & & & -.164 & .103 & -.131 \\
\hline Emotions Neutral & & & & & -.096 & .072 & -.110 \\
\hline & $R^{2}$ & & .145 & & & .371 & \\
\hline & $R_{a d j}^{2}$ & & .130 & & & .343 & \\
\hline & $\square R^{2}$ & & .145 & & & .226 & \\
\hline & $F$ & & 9.659 & & & 13.110 & \\
\hline
\end{tabular}

Note. An * indicates a unique significant predictor variable at $p<.05$. 
Analysis of regression coefficients indicated that Emotions Positive, $\beta=.424, t=$ 4.675, $p<.01$, and Emotions Neutral, $\beta=-.204, t=-2.213, p<.01$, emerged as the only significant predictors when all variables were in the model. The squared part correlations revealed that Emotions Positive uniquely predicted $15.5 \%$ of the variance in Intent to Leave/Volunteer.

Since Trainer Likeability emerged as strong predictors of Intent to Leave/Planning in the final model, organizations in the process of creating new training programs or improving existing ones should focus not only on the emotional experience of their new employees, but also on the likeability of the trainer who is implementing the program. Beta weights for the final regression model can be found in Table 11 .

The hierarchical multiple linear regression analysis for the subscale of Intent to Leave indicated that $11.2 \%$ of the variance in Intent to Leave/Planning could be predicted by control variables, $R_{a d j}^{2}=.097, F(2,114)=7.218, p<.01$. In the second step, after controlling for trainer clarity and likeability, the predictor variables (emotions scales) resulted in a significant change, uniquely accounting for an additional $13.4 \%$ of the variance, $\Delta F(3,111)=6.562, p<.01$. Overall, the model accounted for $24.6 \%$ of the variance in Intent to Leave/Planning, $R_{a d j}^{2}=.212, F(5,111)=7.247, p<.01$. Thus, the significant results of the regression procedure indicated that the combination of the emotion scales was able to account for a significant amount of variance in the dependent variable, after statistically controlling for trainer clarity and likeability. Descriptive statistics for the predictor and dependent variables in the final model can be found in Table 12. 
Table 11

Beta Weights for Intent to Leave/Volunteer Model

\begin{tabular}{|c|c|c|c|c|c|c|c|}
\hline \multirow[b]{2}{*}{ Variable } & & \multicolumn{3}{|c|}{ First Block } & \multicolumn{3}{|c|}{ Second Block } \\
\hline & & $B$ & $S E B$ & $\square$ & $B$ & $S E B$ & $\square$ \\
\hline Trainer Likeability & & .236 & .132 & .214 & .184 & .123 & .166 \\
\hline Trainer Clarity & & -.008 & .172 & -.005 & -.129 & .161 & -.090 \\
\hline Emotions Positive & & & & & .476 & .102 & $.424^{*}$ \\
\hline Emotions Negative & & & & & .148 & .118 & .116 \\
\hline Emotions Neutral & & & & & -.182 & .082 & $-.204 *$ \\
\hline & $R^{2}$ & & .044 & & & .21 & \\
\hline & $R_{a d j}^{2}$ & & .027 & & & .17 & \\
\hline & $\square R^{2}$ & & .044 & & & .16 & \\
\hline & $F$ & & 2.636 & & & 5.901 & \\
\hline
\end{tabular}

Note. An * indicates a unique significant predictor variable at $p<.05$.

Analysis of regression coefficients indicated that Trainer Likeability, $\beta=-.244, t$ $=-2.243, p=.02$, Emotions Positive, $\beta=-.276, t=-3.116, p<.01$, and Emotions Negative, $\beta=.194, t=-2.150, p=.03$, emerged as the only significant predictors when all variables were in the model. The squared part correlations revealed that Trainer Likeability uniquely predicted $3.4 \%$ of the variance in Intent to Leave/Planning Emotions Positive uniquely predicted $6.6 \%$ of the variance, and Emotions Negative uniquely predicted $3.1 \%$ of the variance. 
Table 12

Beta Weights for Intent to Leave/Planning Model

\begin{tabular}{|c|c|c|c|c|c|c|}
\hline \multirow[b]{2}{*}{ Variable } & \multicolumn{3}{|c|}{ First Block } & \multicolumn{3}{|c|}{ Second Block } \\
\hline & $B$ & $S E B$ & $\square$ & $B$ & $S E B$ & $\square$ \\
\hline Trainer Likeability & -.437 & .171 & $-.296^{*}$ & -.360 & .160 & $-.244 *$ \\
\hline Trainer Clarity & -.109 & .221 & -.057 & .039 & .210 & .020 \\
\hline Emotions Positive & & & & -.414 & .133 & $-.276^{*}$ \\
\hline Emotions Negative & & & & .330 & .153 & $.194 *$ \\
\hline Emotions Neutral & & & & .125 & .107 & .105 \\
\hline$R^{2}$ & & .112 & & & .24 & \\
\hline$R_{a d j}^{2}$ & & $.09^{\prime}$ & & & .21 & \\
\hline$\square R^{2}$ & & .112 & & & .13 & \\
\hline$F$ & & 7.218 & & & 7.247 & \\
\hline
\end{tabular}

Note. An * indicates a unique significant predictor variable at $p<.05$.

\section{Newcomer Socialization}

The regression model investigated if an employee's perception of socialization into their new organization could be predicted by increased experience of positive emotions and decreased by the increase of negative emotions during training, after controlling for trainer likeability and trainer clarity. Therefore, hierarchical multiple linear regression analyses were conducted to predict Socialization from the positive and negative emotions scales.

Results of the hierarchical multiple linear regression analysis indicated that $10.6 \%$ of the variance in Socialization/History could be predicted by the control variables, $R^{2}{ }_{a d j}$ $=.091, F(2,114)=6.794, p<.01$. In the second step, after again controlling for trainer likeability and trainer clarity, the predictor variables did not result in a significant change, uniquely accounting for an additional $3.7 \%$ of the variance, $\Delta F(3,111)=1.600, p>.01$. Overall, the model accounted for $14.4 \%$ of the variance in Employee Socialization, $R^{2}$ adj $=.105, F(5,111)=3.720, p<.01$. Thus, the significant results of the regression 
procedure indicated that the linear combination of the predictor variables (emotions scales) was able to account for a significant amount of variance in the dependent variable, Employee Socialization, after statistically controlling for trainer likeability and trainer clarity. Analysis of regression coefficients indicated that no variables emerged as significant predictors when all variables were in the model. See Table 13 for descriptive statistics for the predictor and dependent variables.

Table 13

Beta Weights for Socialization/History Model

\begin{tabular}{|c|c|c|c|c|c|c|c|}
\hline \multirow[b]{2}{*}{ Variable } & & \multicolumn{3}{|c|}{ First Block } & \multicolumn{3}{|c|}{ Second Block } \\
\hline & & $B$ & $S E B$ & $\square$ & $B$ & $S E B$ & $\square$ \\
\hline Trainer Likeability & & .146 & .115 & .146 & .119 & .115 & .119 \\
\hline Trainer Clarity & & 274 & 149 & 212 & .231 & .151 & 179 \\
\hline Emotions Positive & & & & & .154 & .095 & .153 \\
\hline Emotions Negative & & & & & .037 & .110 & .032 \\
\hline Emotions Neutral & & & & & -.133 & .077 & -.166 \\
\hline & $R^{2}$ & & .106 & & & .144 & \\
\hline & $R_{a d j}^{2}$ & & .091 & & & 105 & \\
\hline & $\square R^{2}$ & & .106 & & & .037 & \\
\hline & $F$ & & 6.794 & & & 3.720 & \\
\hline
\end{tabular}

Note. An* indicates a unique significant predictor variable at $p<.05$.

The results of the hierarchical multiple linear regression analysis indicated that $8.5 \%$ of the variance in Employee Socialization/Politics could be predicted by control variables, $R^{2}{ }_{a d j}=.069, F(2,114)=5.273, p<.01$. In the second step, after controlling for trainer clarity and likeability, the predictor variables (emotions scales) did not result in a significant change, uniquely accounting for an additional $4.4 \%$ of the variance, $\Delta F(3$, $111)=1.878, p>.01$. Overall, the model accounted for $12.9 \%$ of the variance in Employee Socialization, $R_{a d j}^{2}=.090, F(5,111)=3.285, p<.01$. Thus, the significant 
results of the regression procedure indicated that the combination of the emotion scales was able to account for a significant amount of variance in the dependent variable, after statistically controlling for trainer clarity and likeability. Descriptive statistics for the predictor and dependent variables in the final model can be found in Table 14.

Table 14

Beta Weights for Socialization/Politics Model

\begin{tabular}{|c|c|c|c|c|c|c|}
\hline \multirow[b]{2}{*}{ Variable } & \multicolumn{3}{|c|}{ First Block } & \multicolumn{3}{|c|}{ Second Block } \\
\hline & $B$ & $S E B$ & $\square$ & $B$ & $S E B$ & $\square$ \\
\hline Trainer Likeability & -.106 & .117 & -.107 & -.130 & .116 & -.131 \\
\hline Trainer Clarity & .449 & .151 & $.348 *$ & .419 & .152 & $.325^{*}$ \\
\hline Emotions Positive & & & & .127 & .096 & .125 \\
\hline Emotions Negative & & & & .103 & .111 & .089 \\
\hline Emotions Neutral & & & & -.173 & .078 & $-.215^{*}$ \\
\hline$R^{2}$ & & .085 & & & .12 & \\
\hline$R_{a d j}^{2}$ & & .069 & & & .09 & \\
\hline$\square R^{2}$ & & .085 & & & .04 & \\
\hline$F$ & & 5.273 & & & 3.285 & \\
\hline
\end{tabular}

Note. An $*$ indicates a unique significant predictor variable at $p<.05$.

Analysis of regression coefficients indicated that Trainer Clarity, $\beta=.325, t=$ $2.760, p<.01$, emerged as the only significant predictor when all variables were in the model. The squared part correlations revealed that Trainer Clarity uniquely predicted $6.0 \%$ of the variance in Employee Socialization.

The final regression for the Research Question indicated that 7.6\% of the variance in Employee Socialization/Performance Proficiency could be predicted by control variables, $R_{a d j}^{2}=.060, F(2,114)=4.710, p<.01$. In the second step, after controlling for trainer clarity and likeability, the predictor variables (emotions scales) did not result in a significant change, uniquely accounting for an additional $1.7 \%$ of the variance, $\Delta F(3$, 
$111)=0.683, p>.01$. Overall, the model accounted for $9.3 \%$ of the variance in Employee Socialization, $R_{a d j}^{2}=.052, F(5,111)=2.278, p>.01$. Thus, the non-significant results of the regression procedure indicated that the combination of the emotion scales were not able to account for a significant amount of variance in the dependent variable, after statistically controlling for trainer clarity and likeability.

Analysis of regression coefficients indicated that Trainer Clarity, $\beta=.311, t=$ $2.590, p<.01$, emerged as the only significant predictors when all variables were in the model. The squared part correlations revealed that Trainer Clarity uniquely predicted $5.4 \%$ of the variance in Employee Socialization. Thus, according to the final regression model, emotions, whether positive, negative, or somewhat neutral, are not significant predictors of new employee socialization. However, Trainer Clarity is indeed a significant predictor of socialization.

Although Trainer Clarity demonstrated significance in the first block of the hierarchical regression, once the predictor variables were considered, these demographic variables no longer accounted for a significant amount of unique variance in Employee Socialization. In addition, since Trainer Clarity emerged as a strong predictor of Employee Socialization in the final model, organizations in the process of creating new training programs or improving existing ones should focus not only on the emotional experience of their new employees, but also on the clarity of the trainer who is implementing the program. Beta weights for the final regression model can be found in Table 15. 
Table 15

Beta Weights for Socialization/Performance Proficiency Model

\begin{tabular}{|c|c|c|c|c|c|c|c|}
\hline \multirow[b]{2}{*}{ Variable } & & \multicolumn{3}{|c|}{ First Block } & \multicolumn{3}{|c|}{ Second Block } \\
\hline & & $B$ & $S E B$ & $\square$ & $B$ & $S E B$ & $\square$ \\
\hline Trainer Likeability & & -.082 & .085 & -.113 & -.093 & .086 & -.128 \\
\hline Trainer Clarity & & .314 & .110 & $.335^{*}$ & .292 & .113 & $.311 *$ \\
\hline Emotions Positive & & & & & .092 & .071 & .125 \\
\hline Emotions Negative & & & & & .042 & .082 & .050 \\
\hline Emotions Neutral & & & & & -.052 & .058 & -.089 \\
\hline & $R^{2}$ & & .07 & & & .09 & \\
\hline & $R_{a d j}^{2}$ & & .06 & & & .05 & \\
\hline & $\square R^{2}$ & & .07 & & & $.01^{\prime}$ & \\
\hline & $F$ & & 4.710 & & & 2.278 & \\
\hline
\end{tabular}

Note. An $*$ indicates a unique significant predictor variable at $p<.05$.

\section{Summary}

As seen above through the multiple regression models, the predictor variables of positive and negative emotions accounted for much of the variance in job satisfaction, employee intent to leave, and newcomer socialization. The clarity and likeability of the trainer facilitating these training programs were more significant than initially predicted. Both trainer clarity and likeability were held constant in the above tests, but were significant predictors of several variables, thus providing reason to consider them when creating and implementing such training programs. Though some of these predictor variables did not account for as much variance as initially hypothesized, they are still important to consider in training programs. 


\section{CHAPTER IV \\ DISCUSSION}

The present study investigated the role that emotions, both positive and negative, play in initial training programs for new employees, and what, if any, are the long-term effects of these emotional experiences. Though there has been past research on emotions in the workplace, communication scholars have neglected to investigate the role emotions play in new employee orientation or training programs, or their effects. Scholars have ignored the role of emotions during training programs until now. Through quantitative research methods and the surveying of working professionals, the present study found that a new employee's emotional experience during their orientation program does have a lasting effect on not only themselves, but also the organization as a whole. Aside from these emotional experiences, this study supports how critical a role the trainer or facilitator has in the same long-term effects.

\section{Summary of Findings}

Through regression models, results show the importance of not only the facilitator of new employee orientation programs, but also the employee's emotional experience during these programs. Also, positive and negative emotions were significant predictors of the same variables in the long-term for new employees.

Although not all hypotheses were supported, the present data shows the importance of new employees' emotional experience during their orientation programs. 
Not only are these emotions relevant during the initial training programs, but also down the road. They have the potential to affect the employee's job satisfaction, intent to leave the organization, and even the extent to which they are socialized, or feel part of the organization in which they work.

\section{Factor Analysis}

The closed-ended survey items used in this study are a combination of existing items from published scales and several original items. There were many existing surveys that claimed to measure the variables in this study. However, upon further investigation into each of these existing surveys, the researcher found that the survey items in each scale did not quite measure this study's variables of job satisfaction, intent to leave, socialization, trainer clarity, and trainer likeability in the way that the present study attempted to measure them. Also, many of the existing surveys asked the survey items with a response option of "yes" or "no," whereas the current study sought to measure each survey item on a 5-point Likert scale. In order to use existing scales to measure the present variables, the survey items from each existing scale that seemed to fit the current study were chosen and adapted to a 5-point Likert scale. In some cases, the number of questions that could be used from the existing scales seemed too short. In these cases, the co-principal investigator created original items to add to the existing items. These original survey items were created to measure each of the variables in a way that the existing items neglected to, but that was critical for the current research.

\section{Regression Models}

The first hypothesis investigated the effects of an increase in positive emotions and predicted later reports of increased job satisfaction for new employees. The results of 
the data analysis show that Emotions Positive, Trainer Clarity, and Emotions Negative, predict Job Satisfaction. The more positive emotions a new employee experiences during their initial training program, the more job satisfaction they will perceive. The clearer a trainer is during the initial training program, the more job satisfaction the new employee will perceive. Also, the greater the level of negative emotions a new employee experiences, the less job satisfaction they will perceive, supporting $\mathrm{H} 2$.

Hypothesis 2 investigated the reverse of H1. It looked at the effects of an increased number of negative emotions and predicted decreased job satisfaction if more negative emotions were experienced. Trainer Clarity, and Emotions Positive, all were predictors of Job Satisfaction. As in H1, the clearer the trainer is during the initial orientation program, the more job satisfaction the new employee will perceive. An increase in positive emotions will lead to an increase of job satisfaction. These results do not support $\mathrm{H} 2$.

Hypothesis 3 predicted that positive emotions experienced by new employees during initial training programs would predict their decreased intent to leave the organization. Emotions positive and trainer likeability were both predictors of employee intent to leave, as shown through data analysis. The more positive emotions a new employee experiences during their initial training program, the less intent they will feel to leave the organization, thus supporting H3. Also, the more likeable the new employee finds the trainer, the less likely they will be to leave the organization, which was not initially hypothesized.

The fourth hypothesis predicted the reverse of $\mathrm{H} 3$, and explored the effects of negative emotions experienced by new employees. $\mathrm{H} 4$ predicted that an increase in 
negative emotions would increase the new employees' intent to leave the organization. Positive emotions were predictors of intent to leave for this hypothesis, as seen in the data analysis. The more positive emotions a new employee experiences, the less likely they will be to leave the organization. These results did not show support of H4.

Finally, the single research question explored the role of emotions, both positive and negative, in predicting perceptions of socialization. The results of the data analysis show that negative emotions are a predictor of newcomer socialization. Also, the clearer and more likeable the trainer is during initial training, the more socialized into the organization the new employee will feel, which was not originally hypothesized. However, the more negative emotions a new employee experiences during initial training, the less socialized the new employee will feel, which answered the Research Question.

\section{Implications}

The long-term effects of new employee emotional experiences are an integral component of initial training programs in organizations. Thus, positive and negative emotions provide a framework for training programs in an organizational context. In fact, much of the emotional experience new employees experience involves the clarity and likeability of the trainer (Simonds, 1997). Results of the present research offer several practical and theoretical implications to trainers, scholars, and organizations.

\section{Practical Implications}

Almost all organizations implement new employee training programs or training programs of some kind for their employees. These findings serve these organizations well. From the present results, any organization that creates or implements training 
programs should be aware of the importance of both the trainer facilitating the training, as well as the emotional experiences of their employees. The trainer plays a crucial role in training programs (Scannell \& Donaldson, 2000). If a new employee is a part of a training program with a trainer who is likeable and very clear in their facilitation of the training, there are positive long-term effects, as supported by Fredrickson's (2004) broaden-and-build theory. Thus, organizations need to pay special attention to clarity and personal likeability of the facilitator they choose, especially for new employee training or orientation programs. This person is one of the first individuals the new employees will meet, and therefore makes a large impression on them. Choosing a trainer or orientation facilitator should be a task that is taken seriously within any organization, and should be an important process (Allen, 1996). The person or people chosen to take on this crucial responsibility should be aware of the effect their clarity of information and likeability have on the new employees they are working with. Also, the new employees will likely associate their training program with this person as long as they are with the organization (Kramer, 1993). It is important for the organization, as well as the trainer, to be aware of the possibility that the new hires will associate their training with the trainer.

More importantly, however, are the emotional experiences of new employees. Until now, these emotional experiences have been an afterthought when it comes to initial orientation or training program. As shown in the results above, employees' emotional experience to their initial training stays with them long after the training program has ended. Organizations that implement training, as well as those who work in the training industry must pay special attention to the emotional experience of new employees during their training, both positive and negative (Fredrickson, 2000). Positive and negative 
emotional experiences have lasting effects on new employees. An abundance of positive emotions will make an employee more satisfied in their job in the long run, as well as making them less likely to have thoughts of leaving the organization. If an employee is satisfied in their job and plans to stay in the organization for the foreseeable future, this is beneficial for the organization. These positive emotions also predict perceptions of being more socialized into the organization than if they had not had a positive emotional experience. The same is true for the opposite. An abundance of negative emotions during initial training programs leads to decreased job satisfaction, increased intent to leave, and perceptions of feeling less socialized or part of the organization. These findings imply that organizations need to pay special attention to the emotional reactions of their new employees during their initial training program (Fredrickson, 2004). In sum, early emotions have the ability to predict employee success later on in the employee's time at the organization.

Past research on emotions in the workplace has neglected to investigate emotions during initial training programs, and thus, their long-term effects after training. The emotions new employees experience during their training program, usually before they even begin their new position, will be remembered for some time, and will affect their perceptions of the organization for which they work (Fredrickson, 2004). These emotions have a significant effect on the employee's job satisfaction, intent to leave the organization, and the extent to which they feel socialized into the organization (Kramer, 1993). The more severe the emotional experience, either positive or negative, the more likely an employee is to remember it (Grama \& Botone, 2009). Just as the perception of the trainer stays with employees in the long-run, so do the memories of their emotional 
experiences. Emotions are critical in organizations, especially early on for new employees. Thus, organizations need to start paying special attention to the emotional experience of all of their employees, namely their new hires, as these experiences will stay with them throughout their time with that organization.

\section{Theoretical Implications}

Broaden-and-build theory had never been applied to the workplace until this study. The current research shows the theory's ability to be applied to other more diverse contexts. Broaden-and-build had been used often when talking about resilience in individuals' lives when studying survival (Fredrickson, 2000). Now, the theory posits that it has application in other areas, namely the workplace. Organizational communication scholars can feel confident using this theory in their research when examining the emotions of employees. Not only can broaden-and-build theory be applied to initial training programs, but it would be interesting to use it at different points in an organization. For example, it would be interesting to apply broaden-and-build theory to an initial disciplinary meeting with their supervisor. According to the results of this study, broaden-and-build theory has the ability to predict the job satisfaction, intent to leave, and socialization of the disciplined employee. Broaden-and-build theory has the ability to predict the future of individuals not only in terms of survival, but also in other aspects of life.

Most importantly, the present findings show the application of broaden-and-build theory in a way it has not been used in the past. In past emotions research, broaden-andbuild theory has focused solely on the positive emotions and their effects on individuals in the long-run (Fredrickson, 2004). This research applied the theory in the workplace 
and tested the effects of both positive and negative emotions. The current research demonstrates the scope of the theory and its ability to predict long-term effects of emotions of any valence, which had not been done before.

\section{Limitations}

Like all studies, this work is not without limitations. The first of the limitations includes the sample size. Due to the very specific participant pool (working adult professionals who have gone through an initial training program), it was difficult to obtain participants. Through a snowball sample, we had a total of 115 participants, though we aimed for more than 200. Along with the number of participants, many participants began the survey and either did not begin it at all, or stopped before completing it. This is likely due to the fact that many participants began the survey on a smart phone or tablet and decided it was too long or that it would be easier done on a computer. With the limited resources and limited amount of time, the survey had to be closed and data had to be collected with the amount of participants there were.

Another limitation of the present study is the use of existing scales and the addition to original items that were created for the current study. There were issues with instrumentation that were revealed through factor analysis. Although originally reported for many of the pre-existing scales, factor analyses needed to be calculated again for this study because those scales were not used in their entirety or because original items were created and added to the existing scales.

The present study did not take into account what was causing these initial positive or negative emotional experiences. The survey instrument asked participants questions regarding the valence of their emotional reactions to training, but not what caused these 
emotions. Also, the present study did not compare participants across industries, as emotional triggers and thus emotional reactions differ across industries.

\section{Future Research Directions}

Future research in this area should examine the crucial role and the importance of the trainer or facilitator of these training programs. Trainer likeability and clarity, though held constant for purposes of this study, are important variables to account for when investigating training experiences. More research should identify characteristics and behaviors of trainers in orientation programs and the effect they have on employees and the organization in the long run.

Also, future directions in this research area should investigate more deeply the long-term effects of negative emotions, in and out of the workplace. Broaden-and-build theory focuses on the long-term effects of positive emotions, though the opposite can be implied for negative emotions. Broaden-and-build theory should be applied to other situations in order to focus on the negative emotions specifically. Not only can broadenand-build theory be applied to initial training programs, but it would be interesting to use it at different points in an organization. For example, it would be interesting to see how broaden-and-build could be studied starting with an initial encounter between supervisor and subordinate, such as in a workplace disciplinary conversation. Scholars could look at the theory in such examples and predict how the employee would view their job and the organization as a whole for the foreseeable future.

Interesting future research should investigate emotional triggers during training programs. Now that the long-term effects of positive and negative emotions on job satisfaction, intent to leave, and perceptions of socialization are known, researchers 
should investigate the stimuli that trigger emotional reactions during training programs. It is important to examine what factors affect emotional reactions, or in other words, determine the various sources of positive and negative emotions during initial training programs. Going even further, future research could compare emotional reactions to training across industries. The stimuli in industries vary, as would the emotional reactions to these stimuli.

\section{Conclusion}

In conclusion, the most important finding that can be reached from the present study is the importance of the emotions experienced by these new employees. Results indicate that all emotions are significant predictors in the long run of the organization, and it is fair to say that trainers should avoid ignoring these emotions. The present study represents steps in the iterative process of developing a line of research concerning new employee emotions and the long-term effects of such emotions. From here, future studies should continue to explore the negative emotions experienced in the work place, specifically during initial training and orientation programs. The findings revealed above indicate progress in this line of research and raise other questions to be addressed in the future. At the very least, a new survey instrument for exploring new employee emotions during initial training programs has withstood the scrutiny of factor analysis procedures and reliability analysis. Furthermore, several significant predictors of new employees' satisfaction, socialization, and intent to leave the organization have been identified through regression models. 


\section{REFERENCES}

Abrantes, J. L., Seabra, C., \& Lages, L. F. (2007). Pedagogical affect, student interest, and learning performance. Journal of Business Research, 60(9), 960-964. doi: 10.1016/j.jbusres.2006.10.026

Allen, B. J. (1996). Feminist standpoint theory: A black woman's (re)view of organizational socialization. Communication Studies, 47, 257-271. Retrieved from: http://www.tandfonline.com/

Andersen, P. A., \& Guerrero, L. K. (1998). Principles of communication and emotion in social interaction. Handbook of communication and emotion: Theory, applications, and contexts (pp. 49-96). San Diego, CA: Academic Press.

Arslan, R., \& Acar, B. N. (2013). A research on academics on life satisfaction, job satisfaction and professional burnout. Journal of Faculty of Economics \& Administrative Sciences, 18, 282-298. Retrieved from:

http://iibfdergi.sdu.edu.tr/en

Ashkanasay, N., \& Daus, C. (2002). Emotion in the workplace: The new challenge for managers. Academy of Management Executives, 16, 76-86. doi:

10.5465/AME.2002.6640191

Astrauskaite, M., Vaitkevicius, R., \& Perminas, A. (2011). Job satisfaction survey: A confirmatory factor analysis based on secondary school teachers' sample. International Journal of Business and Management, 6(5) 41-50. Retrieved from http://www.ccsenet.org/journal/index.php/ijbm 
Averill, J. R., \& More, T. A. (2000). Happiness. In M. Lewis, \& J. M. Haviland-Jones (Eds.), Handbook of emotions ( $2^{\text {nd }}$ ed., pp. 663-676). New York, NY: The Guilford Press.

Babad, E., \& Walbott, H. G. (1986). The effects of social factors on emotional reactions. In K. Scherer, H. G. Walbott, \& A. Summerfield, (Eds.), Experiencing emotions: A cross-cultural study (pp. 154-172). London, UK: Cambridge University Press. Bose, J. (2001). Nonresponse bias analyses at the National Center for Education Statistics. Proceedings of Statistics Canada Symposium 2001. Retrieved from http://www.fcsm.gov/committees/ihsng/StatsCan2_JB.pdf

Bowes, J. M., \& Goodnow, J. J. (1996). Work for home, school, or labor force: The nature and sources of changes in understanding. Psychological Bulletin, 119, 300321. doi: 10.1037/0033-2909.119.2.300

Bruner, J. S., \& Tagiuri, R. (1954). The perception of people. In G. Lindzey (Ed.), Handbook of social psychology (vol. 2, pp. 634-654). Reading, MA: AddisonWesley.

Bullis, C., \& Bach, B. W. (1989). Socialization turning points: An examining of change in organizational identification. Western Journal of Speech Communication, 53, 273-293. Retrieved from http://www.tandfonline.com/loi/rwjc20

Chao, G. T., O’Leary-Kelly, A. M., Wolf, S., Klein, H. J., \& Gardner, P. D. (1994). Organizational socialization: Its content and consequences. Journal of Applied Psychology, 79(5), 730-743. doi: 10.1037/0021-9010.79.5.730 
Cohn, M. A., Fredrickson, B. L., Brown, S. L., Mikels, J. A., \& Conway, A. M. (2009). Happiness unpacked: Positive emotions increase life satisfaction by building resilience. Emotion, 9, 361-368. doi: 10.1037/a0015952

Dillman, D. A. (2000). Mail and Internet surveys: The tailored design method (2 $2^{\text {nd }}$ ed.). New York, NY: John Wiley.

Dijk, W. W., Zeelenberg, M., \& Pligt, J. (1999). Not having what you want versus having what you do not want: The impact of type of negative outcome on the experience of disappointment and related emotions. Cognition and Emotion, 13, 129-148. doi: $10.1080 / 026999399379302$

Feeney, J. A. (2005). Hurt feelings in couple relationships: Exploring the role of attachment and perceptions of personal injury. Personal Relationships, 12, 253271. doi: 10.1111/j.1350-4126.2005.00114.x

Fineman, S. (2003). Understanding emotion at work. Thousand Oaks, CA: Sage.

Flanagin, A. J., \& Waldeck, J. H. (2004). Technology use and organizational newcomer socialization. Journal of Business Communication, 41, 137-165. doi: $10.1177 / 0021943604263290$

Fredrickson, B. L. (2000). Why positive emotions matter in organizations: Lessons from the broaden-and-build model. The Psychologist-Manager Journal, 56, 218-226. doi: 10.1037//0003-66X.56.3.218

Fredrickson, B. L. (2001). The role of positive emotions in positive psychology: The broaden-and-build theory of positive emotions. American Psychologist, 4, 131142. doi: 10.1037/0003-066X.56.3.218 
Fredrickson, B. L. (2004). The broaden-and-build theory of positive emotions. The Journal of Faculty of Economics \& Administrative Sciences, 18, 282-298. doi: $10.1098 /$ rstb. 2004.1512

Fridlund, A. J. (1992). The behavioral ecology and sociality of human faces. Review of Personality and Social Psychology, 13, 90-121. Retrieved from http://psr.sagepub.com/

Galatzer-Levy, I., Brown, A. D., Henn-Haase, C., Metzler, T. J., Neylan, T. C., \& Marmar, C. R. (2013). Positive and negative emotion prospectively predict trajectories of resilience and distress among high-exposure police officers. American Psychological Association, 13, 545-553. doi: 10.1037/a0031314

Gallagher, E. B., \& Sias, P. M. (2009). The new employee as a source of uncertainty: Veteran employee information seeking about new hires. Journal of Communication, 73, 23-46. doi: 10.1080/10570310802636326

Goffman, E. (1961). Encounters: Two studies in the sociology of interaction. Indianapolis, IN: Bobbs-Merrill.

Goleman, D. (2002). The new leaders: Transforming the art of leadership into the science of results. London, UK: Little, Brown and Company.

Grama, B., \& Botone, D. (2009). The role of emotions in organizational behaviour. Annals of the University of Petrosani Economics, 9, 315-320.

Hareli, S., \& Parkinson, B. (2008). What's social about social emotions? Journal for the Theory of Social Behavior, 38, 131-156. doi: 10.1111/j.1468-5914.2008.00363.x 
Hart, Z. P. (2012). Message content and sources during organizational socialization. Journal of Business Communication, 49, 191-209. doi: $10.1177 / 0021943612446731$

Hochschild, A. (1983). The managed heart. Berkeley, CA: University of California Press. Hoffner, C. A., Levine, K. J., \& Toohey, R. A. (2008). Socialization to work in late adolescence: The role of television and family. Journal of Broadcasting \& Electronic Media, 52, 282-302. doi: 10.1080/08838150801992086

Jablin, F. M., \& Krone, K. J. (1987). Organizational assimilation. In C. R. Berger \& S. H. Chaffee (Eds.) Handbook of communication science (pp. 711-746). Newbury Park, CA: Sage.

Johnson-Liard, P. N., \& Oatley, K. (2000). Cognitive and social construction in emotion. In M. Lewis, \& J. M. Haviland-Jones (Eds.), Handbook of emotions ( $2^{\text {nd }}$ ed., pp. 458-475). New York, NY: The Guilford Press.

Johnstone, T., \& Scherer, K. R. (2000). Vocal communication of emotions. In M. Lewis, \& J. M. Haviland-Jones (Eds.), Handbook of emotions (2 ${ }^{\text {nd }}$ ed., pp. 220-235). New York, NY: The Guilford Press.

Jones, G. R. (1986). Socialization tactics, self-efficacy, and newcomers' adjustments to organizations. Academy of Management Journal, 29, 262-279. doi: $10.2307 / 256188$

Judge, T. A., Bono, J. E., \& Locke, E. A. (2000). Personality and job satisfaction: The mediating role of job characteristics. Journal of Applied Psychology, 85, 237-249. doi: $10.1037 / 0021-9010.85 .2 .237$ 
Keltner, D., \& Ekman, P. (2000). Facial expression of emotion. In M. Lewis, \& J. M. Haviland-Jones (Eds.), Handbook of emotions ( ${ }^{\text {nd }}$ ed., pp. 236-249). New York, NY: The Guilford Press.

Keltner, D., \& Haidt, J. (2001). Social functions of emotions. In T. Mayne \& G. A. Bonanno (Eds.), Emotions: Current issues and future directions (pp. 192-213). New York, NY: Guilford Press.

Klemmer, E. T., \& Snyder, F. W. (1972). Measurement of time spent communicating. Journal of Communication, 20, 142. Retrieved from http://onlinelibrary.wiley.com/journal/10.1111/(ISSN)1460-2466

Knobloch, L. K., \& Metts, S. (2013). Emotion in relationships. The Oxford handbook of close relationships (pp. 514-534). doi: 10.1093/oxfordhb/9780195398694. 013.0023

Kramer, M. W. (1993). Communication and uncertainty reduction during job transfers: Leaving and joining processes. Communication Monographs, 60, 178-198. doi: $10.1080 / 03637759309376307$

Larkin, R., \& Burgess, J. (2013). The paradox of employee retention for knowledge transfer. Employment Relations Record, 13, 32-43. Retrieved from: http://www.pera.net.au/

Lemerise, E. A., \& Dodge, K. A. (2000). The development of anger and hostile interactions. In M. Lewis, \& J. M. Haviland-Jones (Eds.), Handbook of emotions ( $2^{\text {nd }}$ ed., pp. 594-606). New York, NY: The Guilford Press. 
Lewis, M. (2000). Self-conscious emotions: Embarrassment, pride, shame, and guilt. In M. Lewis, \& J. M. Haviland-Jones (Eds.), Handbook of emotions ( $2^{\text {nd }}$ ed., pp. 623-636). New York, NY: The Guilford Press.

Liu, D., Mitchell, T. R., Lee, T. W., Holtom, B. C., \& Hinkin, T. R. (2012). When employees are out of step with coworkers: How job satisfaction trajectory and dispersion influence individual- and unit-level voluntary turnover. Academy of Management Journal, 55, 1360-1380. doi: 10.5465/amj.2010.0920

Locke, E. A. (1976). The nature and causes of job satisfaction. In M. D. Dunnette (Ed.), Handbook of industrial and organizational psychology (pp. 1297-1349). Chicago: Rand McNally.

Loher, B. T., Noe, R. A., Moeller, N. L., \& Fitzgerald, M. P. (1985). A meta-analysis of the relation of job characteristics to job satisfaction. Journal of Applied Psychology, 70, 280-289. doi: 10.1037/0021-9010.70.2.280

Louis, M. R. (1980). Surprise and sense-making: What newcomers experience when entering unfamiliar organizational settings. Administrative Science Quarterly, 23, 225-251. Retrieved from: http://asq.sagepub.com/

Lupton, D. (1994). Medicine as culture: Illness, disease and the body in Western societies. London, UK: Sage.

Madlock, P. E., \& Chory, R. M. (2014). Socialization as a predictor of employee outcomes. Communication Studies, 65, 56-71. doi: 10.1080/10510974.2013.811429

Meyers, L. S., Gamst, G., \& Guarino, A. J. (2006). Applied multivariate research: Design and interpretation. Thousand Oaks, CA: Sage. 
Mertler, C. A., \& Vannatta, R. A. (2005). Advanced and multivariate statistical methods: Practical application and interpretation ( $3^{\text {rd }}$ ed.). Glendale, CA: Pyrczak.

Mirela, P., \& Iulia, S. I. (2013). Emotions in the organizational environment. Annals of the University of Oradea, Economic Science Series, 22, 1595-1605. Retrieved from http://anale.steconomiceuoradea.ro/en/

Morgan, R. L., \& Heise, D. (1988). Structure of emotions. Social Psychology Quarterly, 51, 19-31. Retrieved from http://www.jstor.org/stable/2786981

Muchinsky, P. (2000). Emotions in the workplace: The neglect of organizational behavior. Journal of Organizational Behavior, 21, 801-805. doi: 10.1002/10991379

Oatley, K., \& Jenkins, J. M. (1996). Understanding emotions. Oxford, UK: Blackwell. Ohman, A. (2000). Fear and anxiety: Evolutionary, cognitive, and clinical perspectives. In M. Lewis, \& J. M. Haviland-Jones (Eds.), Handbook of emotions $\left(2^{\text {nd }}\right.$ ed., pp. 573-593). New York, NY: The Guilford Press.

O’Neill, O. (2009). Workplace expression of emotions and escalation of commitment. Journal of Applied Psychology, 39, 2396-2424. doi: 10.1111/j.15591816.2009.00531.x

O’Reilly, C., \& Chatman, J. (1986). Organizational commitment and psychological attachment: The effects of compliance, identification, and internalization on prosocial behavior. Journal of Applied Psychology, 71, 492-499. Retrieved from http://psycnet.apa.org/journals/apl/ 
Plutchik, R. (2001). The nature of emotions: Human emotions have deep evolutionary roots, a fact that may explain their complexity and provide tools for clinical practice. American Scientist, 89, 344-350. Retrieved from: http://www.americanscientist.org/

Porter, L. W., Steers, R. M., Mowday, R. T., \& Boulian, P. V. (1974). Organizational commitment, job satisfaction, and turnover among psychiatric technicians. Journal of Applied Psychology, 59, 603-609. Retrieved from http://www.apa.org/pubs/journals/apl/index.aspx

Rosin, H. M., \& Korabik, K. (1991). Workplace variables, affective responses, and intention to leave among woman managers. Journal of Occupational Psychology, 64(4), 317-330. Retrieved from http://onlinelibrary.wiley.com/journal/10.1111/(ISSN)2044-8325/issues

Scannell, E. E., \& Donaldson, L. (2000). Human resource development: The new trainer's guide. Cambridge, MA: Perseus.

Schiffrin, H. H., \& Falkenstern, M. (2012). The impact of affect on resource development: Support for the broaden-and-build model. North American Journal of Psychology, 14, 569-584. doi: 10.1108/JSM-02-2013-0051

Simonds, C. J. (1997). Classroom understanding: An expanded notion of teacher clarity. Communication Research Reports, 14, 279-290. Retrieved from http://www.tandfonline.com/loi/rcrr20\#.VE-kWyiAR9k

Spector, P. E. (1997). Job satisfaction: Application, assessment, causes, and consequences. Thousand Oaks, CA: Sage. 
Stratton, M. T., Kass, D. S., \& Rotenberry, P. F. (2011). Affective events theater: Creating teaching moments from film and television to explore emotions in the workplace. Journal of the Academy of Business Education, 12, 1-27. Retrieved from: http://www.abe.sju.edu/

Tuten, T. L., Urban, D. J., \& Bosnjak, M. (2002). Internet surveys and data quality: A review. In B. Batinic, U. Reips, \& M. Bosnjak (Eds.), Online social sciences (pp. 7-26). Seattle, WA: Hogrefe and Huber.

Watt, J. H. (1999). Internet systems for evaluation research. In G. Gay \& T. L. Bennington (Eds.), Information technologies in evaluation: Social, moral, epistemological, and practical implications (pp. 23-43). San Francisco, CA: Jossey-Bass.

Watzlawick, P., Bavelas, J. B., \& Jackson, D. D. (1967). Pragmatics of human communication: A study of interactional patterns, pathologies, and paradoxes. New York, NY: W. W. Norton \& Company.

Weiss, H. M., \& Brief, A. P. (2001). Affect at work: A historical perspective. In R. L. Payne \& C. L. Cooper (Eds.), Emotions at work: Theory, research and applications in management (pp. 133-171). Chichester, UK: Wiley and Sons.

Wong, K., Yik, M., \& Kwong, J. (2006). Understanding the emotional aspects of escalation of commitment: The role of negative affect. Journal of Applied Psychology, 91, 282-297. doi: 10.1037/0021-9010.91.2.282 


\section{APPENDIX \\ COMPLETE SURVEY INSTRUMENT}

Directions: Please think of the most recent job where you completed a training program before you began the position. This may be the position in which you are currently employed. [response options are text boxes and/or number sliders]

1. What industry is/was this job in? [drop-down menu with 'other' box]

2. How long did the training period last? [Please specify the number of days, weeks, or months the program lasted.] days weeks months

3. How many people were in your training group? [Blank number box.]

4. To your knowledge, how much turnover in employee membership is there at this organization?

[Likert-type slider: 1-10 very little to a lot]

5. Indicate the extent to which you can recall the emotions you experienced during my training period.

[Likert-type slider: 1-10 not very clearly to very clearly]

6. Was your training program useful?

[Use 1 for "not at all" to 10 for "very useful"]

Directions: Keeping the same training period in mind, please indicate to what extent you felt the following emotions DURING the training period. [response options range from 1 "did not experience this emotion at all" to 5 "a great deal of this emotion was experienced"]

Emotions during training

1. I felt interested.

2. I felt excited.

3. I felt nervous.

4. I felt afraid.

5. I felt unsure.

6. I felt concerned.

7. I felt eager.

8. I felt happy.

9. I felt passionate.

10. I felt lonely.

11. I felt frustrated.

12. I felt surprised.

13. I felt proud. 
14. I felt hurt.

15. I felt sad.

16. I felt content.

17. I felt disappointed.

18. I felt joyful.

19. I felt angry.

20. I felt confused.

Directions: With this training program in mind, indicate below the extent to which you agree with the following statements. By a training program, we mean a formal and organized orientation program that new employees were expected to complete. [response options range from 1 "strongly disagree" to 5 "strongly agree"]

1. I feel like I fit in here. (satisfaction)

2. I can imagine others not wanting to work here. (satisfaction)

3 . It is clear to me what I need to do at work. (trainer clarity)

4. I do not find my trainer to be pleasant. (trainer likeability)

5. I can see myself working my way up in this company. (intent to leave)

6. I talk with my coworkers about things that are not job-related. (satisfaction)

7. I am not happy with my job. (satisfaction)

8. I have not received direction as to which tasks to complete. (trainer clarity)

9. I am satisfied with my job. (satisfaction)

Directions: With this training program in mind, indicate below the extent to which you agree with the following statements. By a training program, we mean a formal and organized orientation program that new employees were expected to complete. [response options range from 1 "strongly disagree" to 5 "strongly agree"]

\section{$\underline{\text { Socialization }}$}

1. I know very little about the history behind my work group/department. (R)

2. I am not familiar with the organization's customs, rituals, ceremonies, and celebrations. $(\mathrm{R})$

3. I know the organization's long-held traditions.

4. I would be a good resource in describing the background of my work group/department.

5. I am familiar with the history of my organization.

6. I have learned how things "really work" on the inside of this organization.

7. I know who the most influential people are in my organization.

8. I do not have a good understanding of the politics of my organization. (R)

9. I am not always sure what needs to be done in order to get the most desirable work assignments in my area. (R)

10. I have a good understanding of the motives behind the actions of other people in the organization.

11. I can identify the people in this organization who are most important in getting the work done.

12. I have not yet learned "the ropes" of my job. (R) 
13. I have learned how to successfully perform my job in an efficient manner.

14. I have mastered the required tasks of my job.

15. I have not fully developed the appropriate skills and abilities to successfully perform my job. (R)

16. I understand what all the duties of my job entail.

Directions: With this training program in mind, indicate below the extent to which you agree with the following statements. By a training program, we mean a formal and organized orientation program that new employees were expected to complete. [response options range from 1 "strongly disagree" to 5 "strongly agree"]

\section{Job Satisfaction}

1. I sometimes feel my job is meaningless.

2. I like doing the things I do at work.

3. I feel a sense of pride in doing my job.

4. My job is enjoyable.

5. Communications seem good within this organization.

6. The goals of this organization are not clear to me.

7. I often feel that I do not know what is going on with the organization.

8. Work assignments are not fully explained.

Directions: With this training program in mind, indicate below the extent to which you agree with the following statements. By a training program, we mean a formal and organized orientation program that new employees were expected to complete. [response options range from 1 "strongly disagree" to 5 "strongly agree"]

\section{Intent to Leave}

1. My attachment to this organization is primarily based on the similarity of my values and those represented by the organization.

2. What this organization stands for is important to me.

3. I am proud to tell others that I am part of this organization.

4. I feel a sense of "ownership" for this organization rather than being just an employee.

5. Unless I'm rewarded for it in some way, I see no reason to expend extra effort on behalf of this organization.

6. How hard I work for the organization is directly linked to how much I am rewarded.

7. I participate in planning and organizing social events at work (e.g., staff parties).

8. I make suggestions to improve the organization.

9. I attend functions that are not required, but that help the organization's image.

10. I volunteer for tasks that are not required.

11. I comply with the rules and regulations of this organization.

12. At this time in my career, I would quit this job if it were possible.

13. I am actually planning to leave my job within the next six months.

14. I am actively searching for another job right now.

15. I have had thoughts of leaving my job.

Directions: With this training program in mind, indicate below the extent to which you agree with the following statements. By a training program, we mean a formal and 
organized orientation program that new employees were expected to complete. [response options range from 1 "strongly disagree" to 5 "strongly agree"]

Trainer Likeability

1. I liked my trainer as a person.

2. The trainer seemed to have an equal concern for all trainees.

3. My trainer was actively helpful when trainees had difficulty.

4. My trainer was likeable.

5. I enjoyed spending time at work with my trainer.

6. I did not find my trainer to be pleasant.

7. I would enjoy working with my trainer again on future tasks.

8. I would rather not work with my trainer outside of the training program.

Directions: With this training program in mind, indicate below the extent to which you agree with the following statements. By a training program, we mean a formal and organized orientation program that new employees were expected to complete. [response options range from 1 "strongly disagree" to 5 "strongly agree"]

\section{$\underline{\text { Trainer Clarity }}$}

1. My trainer was clear when presenting content.

2. My trainer gave previews of material to be covered in training.

3. My trainer gave summaries when presenting content.

4. My trainer stressed important points in training.

5. My trainer stayed on topic.

6. My trainer clearly explained the objectives for the content being presented.

7. My trainer defined major/new concepts.

8. My trainer communicated organization processes and expectations clearly.

9. My trainer described work tasks and how they should be done.

10. My trainer prepared me for the tasks I would be doing next in my job.

11. My trainer asked if we knew what to do and how to do it. .

12. My trainer pointed out practical applications for training.

13. My trainer provided rules and standards for satisfactory performance.

14. My trainer communicated policies and consequences for violation.

Directions: Please provide a little information about yourself. Responses will be used in aggregate form to compare groups of individuals, but not to identify particular individuals.

\section{Demographic information}

1. What is your biological gender? [Male, female, other]

2. What is your age as of your last birthday? [number slider]

3. What is your race/ethnicity? [Caucasian, African-American, Hispanic, IndianAmerican, bi-racial/mixed, Asian/Pacific Islander, other]

4. How many previous jobs/careers have you held post your educational degree? [number slider]

5. How long has it been since the training period you had in mind? [number slider] 
6. What is your highest level of education? [high school diploma, bachelor's degree, master's degree, doctoral degree]

7. How integral are employee emotions to the job they do? [response options range from 1 "not at all" to 10 "very much so"] 